\title{
Bidirectional EphrinB3/EphA4 Signaling Mediates the Segregation of Medial Ganglionic Eminence- and Preoptic Area-Derived Interneurons in the Deep and Superficial Migratory Stream
}

\author{
Geraldine Zimmer, Judith Rudolph, Julia Landmann, Katrin Gerstmann, André Steinecke, Christin Gampe, \\ and Jürgen Bolz \\ Institut für Allgemeine Zoologie und Tierphysiologie, Friedrich-Schiller-Universität, 07743 Jena, Germany
}

\begin{abstract}
The integration of interneuron subtypes into specific microcircuits is essential for proper cortical function. Understanding to what extent interneuron diversity is regulated and maintained during development might help to reveal the principles that govern their role as synchronizing elements as well as causes for dysfunction. Particular interneuron subtypes are generated in a temporally regulated manner in the medial ganglionic eminence (MGE), the caudal ganglionic eminence, and the preoptic area (POA) of the basal telencephalon. Long-range tangential migration from their site of origin to cortical targets is orchestrated by a variety of attractive, repulsive, membrane-bound, and secreted signaling molecules, to establish the critical balance of inhibition and excitation. It remains unknown whether interneurons deriving from distinct domains are predetermined to migrate in particular routes and whether this process underlies cell type-specific regulation. We found that POA- and MGE-derived cortical interneurons migrate within spatially segregated corridors. EphrinB3, expressed in POA-derived interneurons traversing the superficial route, acts as a repellent signal for deeply migrating interneurons born in the MGE, which is mediated by EphA4 forward signaling. In contrast, EphA4 induces repulsive ephrinB3 reverse signaling in interneurons generated in the POA, restricting this population to the superficial path. Perturbation of this bidirectional ephrinB3/EphA4 signaling in vitro and in vivo leads to a partial intermingling of cells in these segregated migratory pathways. Thus, we conclude that cell contact-mediated bidirectional ephrinB3/EphA4 signaling mediates the sorting of MGE- and POA-derived interneurons in the deep and superficial migratory stream.
\end{abstract}

\section{Introduction}

Cortical interneurons represent a daunting diverse group performing a rich functional variety in inhibition that is likely responsible for the enormous computational capability of the cerebral cortex. Already minor disturbances in number or distribution of interneuron subtypes can lead to severe neurological or neuropsychiatric symptoms described for epilepsy and schizophrenia (Powell et al., 2003; Ikeda et al., 2004; Cobos et al., 2005), which are increasingly regarded as neurodevelopmental disorders (Lewis and Levitt, 2002; Levitt et al., 2004). Thus, deciphering the origin and development of interneuron subtypes not only might contribute to reveal the mechanisms of constructing cor-

\footnotetext{
Received Sept. 14, 2011; accepted 0ct. 25, 2011.

Author contributions: G.Z. and J.B. designed research;G.Z., J.R., J.L., K.G., A.S., and C.G. performed research; G.Z., J.R., and J.L. analyzed data; G.Z. and J.B. wrote the paper.

This work was supported by the Carl Zeiss Foundation and Deutsche Forschungsgemeinschaft Grant Zl-1224/2-1. We thank Christine Raue for excellent technical assistance. We further thank Dr. R. Klein (Max Planck Institute for Neurobiology, Martinsried, Germany) for providing the ephrinB3 knock-out and EphA4-Plap mice.

Correspondence should be addressed to Geraldine Zimmer at her present address, Universitätsklinikum Jena, Institut für Humangenetik, Kollegiengasse 10, 07743 Jena, Germany, E-mail: zimmer_geraldine@yahoo.de; or Jürgen Bolz, Universität Jena, Institut für Allgemeine Zoologie and Tierphysiologie, Erberstrasse 1, 07743 Jena, Germany, E-mail: jurgen.bolz@uni-jena.de.

DOI:10.1523/JNEUROSCI.4690-11.2011

Copyright $\odot 2011$ the authors $\quad 0270-6474 / 11 / 3118364-17 \$ 15.00 / 0$
}

tical circuits but also helps to identify critical pathophysiological events. Distinct subtypes of cortical interneurons are generated in specific domains of the basal telencephalon in a time-dependent fashion. Parvalbumin- and somatostatin-expressing cortical interneurons derive from the medial ganglionic eminence (MGE), while most of the calretinin-positive interneurons are born at later stages in the caudal ganglionic eminence (CGE) (Xu et al., 2004; Butt et al., 2005; Miyoshi et al., 2007). Moreover, the preoptic area (POA) was recently identified as a novel source for cortical interneurons (Gelman et al., 2009). From their site of generation, cortical interneurons perform long-range tangential migration along a deep migratory stream (DMS) and superficial migratory stream (SMS) through the basal telencephalon to reach the cortex, regulated by attractive and repulsive membrane-bound or secreted guidance molecules (Marín and Rubenstein, 2001; Hernández-Miranda et al., 2010). It remains unclear, however, whether interneurons generated in particular domains contribute differentially to the spatially distinct migratory routes and, if so, which factors mediate the sorting.

Eph receptor tyrosine kinases and their ligands, known to regulate axonal guidance, dendritic branching, spine formation, proliferation, and cell migration (Pasquale, 2005; Klein, 2009), are auspicious candidates controlling this process. They can be 
subdivided structurally in two classes, the EphA and the EphB system. EphA receptors bind exclusively to A-ephrins, with exception of EphA4, which also interacts with transmembranal ephrinB ligands. An essential hallmark of the Eph/ephrin family is that both Ephs and ephrins can act as receptor or ligand, enabling bidirectional signaling (Davy and Soriano, 2005).

We found that ephrinB3 and EphA4 are complementarily expressed in the basal telencephalon demarcating distinctively the superficial and deep migratory corridor during tangential migration of MGE- and POA-derived interneurons, which suggests an involvement in the spatial segregation of the two migratory streams. Interneurons arising from the POA express ephrinB3 and migrate along the superficial route, while MGE-derived interneurons express EphA4 and traverse the deep route. Loss-offunction studies indicate that ephrinB3 acts as a repulsive signal for MGE-derived interneurons mediated by EphA4, while EphA4 in turn induces a repulsive response in ephrin $\mathrm{B} 3$-expressing POA cells. Heterozygous ephrinB3/EphA4 double mutants as well as homozygous ephrinB3 knock-out mice reveal misdirected interneurons in the POA and MGE. Thus, bidirectional ephrinB3/ EphA4 signaling is involved in the segregation of POA- and MGE-derived interneurons in the superficial and deep migratory stream.

\section{Materials and Methods}

Mouse strains. Wild-type mice maintained in a C57BL/6 background were used for expression analysis, dissociated single-cell experiments, focal electroporation experiments in the organotypic slice cultures, and ex utero and in utero electroporation experiments. For the grafting experiments and the reaggregation assay, we used the enhanced green fluorescent protein (EGFP)-expressing C57BL/6 mouse strain (Okabe et al., 1997). Heterozygous EphA4-PLAP mutants (Leighton et al., 2001) and/or heterozygous ephrin-B3 knock-out mice (Kullander et al., 2001), both maintained at the C57BL/6 background (received from Dr. R. Klein, Max Planck Institute for Neurobiology, Martinsried, Germany), were used to obtain heterozygous ephrinB3/EphA4 or homozygous ephrinB3 knock-out embryos. Genotyping was confirmed by genomic PCR. For staging of mouse embryos, the day of insemination was considered as embryonic day 1 (E1). All animal procedures were performed in agreement with the institutional regulations of the University of Jena (Jena, Germany).

Plasmids. EphrinB3 shRNA was commercially obtained from Oligoengine (NM_007911-326.HINDIII, NM_007911-326.HINDIII_AS oligo cloned into the pSUPER.gfp+neo_circular vector). As control construct we used the pSUPER.gfp + neo_circular vector (Oligoengine).

In situ hybridization. In situ hybridizations were performed on $20 \mu \mathrm{m}$ coronal cryosections of heads of E14 wild-type embryos using digoxigenin (DIG)-labeled antisense RNA probes. For that purpose, embryos were decapitated and the heads were freshly frozen in liquid nitrogen. Sections were thaw-mounted on SuperFrost Plus slides (Thermo Fisher Scientific). In situ hybridization was performed as described previously (Zimmer et al., 2008). In brief, sections were fixed for $10 \mathrm{~min}$ in $4 \%$ paraformaldehyde (PFA) in PBS at room temperature, permeabilized with $0.2 \mathrm{M} \mathrm{HCl}$, and acetylated with $5 \mathrm{~mm}$ acetic anhydride. Hybridization and washing were performed at high stringency using a probe concentration of $3 \mathrm{ng} / \mu \mathrm{l}$. After blocking with $2 \%$ blocking reagent (Roche), hybrids were detected using an anti-DIG Fab fragment conjugated with alkaline phosphatase (1:750; Roche) and nitroblue tetrazolium chloride/ 5-bromo-4-chloro-indolyl-phosphate as colorigenic substrates. Probes were derived by in vitro transcription in the presence of DIG-11-UTP (Roche) from PCR fragments of respective cDNAs cloned into pBluescript I KS (Stratagene). The EphA4 riboprobe spans the sequence number 75-761 (accession number NM_007936); the ephrinB3 riboprobe spans the sequence number 137-955 (accession number NM_007911.5); ephrinB1, 802-1622 (accession number NM_010110.4); ephrinB2, 755-
1961 (accession number NM_10111.5); EphB1, 609-1480 (accession number NM_001168296.1); EphB2, 1133-2018 (accession number NM_010142.2); EphB3, 2473-3448 (accession number NM_010143.1); EphA3, 257-1253 (accession number NM_010140.3); EphA5, 903-1645 (accession number NM_007937.3); Nrp-2, 738-1540 (accession number NM_010939).

Immunohistochemistry. Immunohistochemistry was performed on 20 $\mu \mathrm{m}$ coronal cryosections of heads of E14 wild-type embryonic brains that were immersion fixed with $4 \%$ PFA in PBS for $4 \mathrm{~h}$ at room temperature. Fixed brains were then cryoprotected overnight with 15 and $30 \%$ sucrose at $4^{\circ} \mathrm{C}$ before freezing in liquid nitrogen for cryosectioning. Slices were treated with the blocking reagent $3 \% \mathrm{BSA}, 10 \%$ normal goat or donkey serum, in PBS with $0.5 \%$ Tween and $0.5 \%$ Triton X-100) for $2 \mathrm{~h}$ before incubating with the primary antibody overnight at room temperature. Secondary antibodies were applied for $2 \mathrm{~h}$ at room temperature. Nuclei were stained with DAPI (100 ng/ml in PBS; Sigma-Aldrich) for $15 \mathrm{~min}$.

For immunocytochemistry in dissociated cells, blocking occurred for $30 \mathrm{~min}$ in 3\% BSA, 10\% normal goat or donkey serum in PBS with $0.3 \%$ Triton X-100. Incubation with the primary antibody diluted in blocking reagent was performed overnight at $4^{\circ} \mathrm{C}$. Cells were then incubated for $1.5 \mathrm{~h}$ with the secondary antibodies and stained with DAPI $(100 \mathrm{ng} / \mathrm{ml}$ in PBS; Sigma-Aldrich) for $10 \mathrm{~min}$ at room temperature. For double immunocytochemistry, the two primary or secondary antibodies were supplied as a mixture. Primary antibodies were as follows: rabbit anti-calbindin (Swant; 1:1000), mouse anti-calbindin (Sigma-Aldrich; 1:500), rabbit anti-EphA4 (Santa Cruz Biotechnology; 1:400), rabbit anti-pSrc418 (Invitrogen; 1:100), mouse anti-PY99-Alexa Fluor 405 conjugate (Santa Cruz Biotechnology; 1:100). Secondary antibodies were as follows: Cy3goat anti-rabbit IgG (1:2000), Alexa 488-goat anti-mouse IgG (1:1000), Cy3-goat anti-mouse IgG (1:2000) (all from Jackson ImmunoResearch Laboratories).

Preparation of dissociated neurons. The E14 embryos of timedpregnant females were removed and decapitated. The embryonic brains were dissected coronally into $250 \mu \mathrm{m}$ slices using a tissue chopper and transferred in Gey's balanced salt solution (GBSS) with $0.65 \%$ glucose. Only brain slices including the POA, MGE, and LGE were chosen. After dissecting the POA domain, the ventricular zone/subventricular zone (VZ/SVZ) and intermediate zone (IMZ) of the MGE were prepared. The tissue was collected in ice-cold HBSS (Invitrogen) supplemented with $0.65 \%$ glucose. After incubation with $0.025 \%$ trypsin in HBSS for $17 \mathrm{~min}$ at $37^{\circ} \mathrm{C}$, the tissue was dissociated into single cells by trituration and filtered through nylon gauze to remove cell aggregates. Neurons were seeded at densities of 300 cells $/ \mathrm{mm}^{2}$ and incubated cultured in DMEM (Invitrogen) supplemented with 10\% fetal bovine serum (FBS), 100 $\mathrm{U} / \mathrm{ml}$ penicillin, $100 \mu \mathrm{g} / \mathrm{ml}$ streptomycin, $0.065 \%$ glucose and $0.4 \mathrm{~mm}$ L-glutamine at $37^{\circ} \mathrm{C}, 5 \% \mathrm{CO}_{2}$ in a humid atmosphere for $1-2 \mathrm{~d}$ in vitro (div). Cells were fixed in 4\% PFA in PBS for $15 \mathrm{~min}$ at room temperature.

Binding assays. Primary neurons (E14) seeded at a density of 300 cells/ $\mathrm{cm}^{2}$ were grown for $24 \mathrm{~h}$ in DMEM supplemented with $10 \% \mathrm{FBS}, 100$ $\mathrm{U} / \mathrm{ml}$ penicillin, $100 \mu \mathrm{g} / \mathrm{ml}$ streptomycin, $0.065 \%$ glucose, and $0.4 \mathrm{~mm}$ L-glutamine. Then $5 \mu \mathrm{g} / \mathrm{ml}$ recombinant EphB1-Fc, EphA4-Fc, or ephrinB3-Fc (R\&D Systems) clustered with $20 \mu \mathrm{g} / \mathrm{ml}$ Alexa 488conjugated anti-human IgG antibody (Invitrogen) was applied for $2 \mathrm{~h}$ at $37^{\circ} \mathrm{C}$ and $5 \% \mathrm{CO}_{2}$ in fresh medium. Then cells were washed briefly in culture medium and fixed with $4 \%$ paraformaldehyde in PBS.

Stripe assays. For the stripe assays, we used silicone matrices normally applied for soluble stripes (Zimmer et al., 2007) as a printing tool according to Gebhardt et al. (2008). We coated the bars $(50 \mu \mathrm{m})$ that separate the channels with $2 \mu \mathrm{g} / \mathrm{ml}$ human ephrinB3-Fc (R\&D Systems) preclustered with $30 \mu \mathrm{g} / \mathrm{ml}$ anti-human IgG-Alexa 488 (Invitrogen) or $2 \mu \mathrm{g} / \mu \mathrm{l}$ EphA4 clustered with $30 \mu \mathrm{g} / \mathrm{ml}$ anti-human IgG-Alexa 488 in PBS for 30 min at $37^{\circ} \mathrm{C}$. After removing the solution, the protein adhered to the silicone was printed to coverslips. Leaving the bars of the silicone matrix adhered to the coverslips, we immediately injected $20 \mu \mathrm{g} / \mathrm{ml}$ human IgG (Fc) fragment (Rockland Immunochemicals) preclustered with 30 $\mu \mathrm{g} / \mathrm{ml}$ unlabeled anti-Fc antibody in PBS (Alexis Biochemicals) into the channels of the silicone matrix. The proteins were allowed to adhere to the coverslip for $1 \mathrm{~h}$, before stripes were finally coated with $19 \mu \mathrm{g} / \mathrm{ml}$ laminin (Sigma-Aldrich) and $5 \mu \mathrm{g} / \mathrm{ml}$ poly-L-lysine (Sigma-Aldrich). 
The double stripes of ephrinB3-Fc and EphA4-Fc were produced accordingly. The printing solution contained either $2 \mu \mathrm{g} / \mathrm{ml}$ recombinant ephrinB3-Fc or EphA4-Fc preclustered with $30 \mu \mathrm{g} / \mathrm{ml}$ Alexa-labeled anti-human IgG antibody. The solution used for injection into the channels contained $20 \mu \mathrm{g} / \mathrm{ml}$ clustered recombinant EphA4-Fc or ephrinB3Fc. As an internal control, we produced stripes of printed ephrinB3-Fc and injected EphA4-Fc as well as stripes of printed EphA4-Fc and injected ephrinB3-Fc protein, which were differentially labeled with 30 $\mu \mathrm{g} / \mathrm{ml}$ Alexa 488- or Alexa 546-conjugated anti-human IgG antibody (Invitrogen). Dissociated cells (300 cells $/ \mathrm{mm}^{2}$ ) were grown for $2 \mathrm{div}$ at $37^{\circ} \mathrm{C}$ and $5 \% \mathrm{CO}_{2}$.

Preparation of organotypic slice cultures. The E14 embryos of an EGFPheterozygous female were removed and decapitated. The wild-type embryonic brains were prepared in Krebs' buffer (126 mM NaCl, $2.5 \mathrm{~mm}$ $\mathrm{KCL}, 1.2 \mathrm{~mm} \mathrm{NaH}_{2} \mathrm{PO}_{4}, 1.2 \mathrm{~mm} \mathrm{MgCl} 2,2.1 \mathrm{~mm} \mathrm{CaCl}_{2}, 10 \mathrm{~mm}$ D-glucose, $12.5 \mathrm{~mm} \mathrm{NaHCO}_{3}$ ), embedded in $4 \%$ low-melt agarose (Roth) at $37^{\circ} \mathrm{C}$ and subsequently dissected coronally into $300 \mu \mathrm{m}$ slices using a vibratome at $4^{\circ} \mathrm{C}$. Slices were transferred into postholding buffer (Krebs' buffer with $1 \mathrm{~m}$ HEPES, $100 \mathrm{U} / \mathrm{ml}$ penicillin, $100 \mu \mathrm{g} / \mathrm{ml}$ streptomycin, and $50 \mu \mathrm{g} / \mathrm{ml}$ gentamicin) for $30 \mathrm{~min}$ at $4^{\circ} \mathrm{C}$. Then the slices were plated on Nucleopore polycarbonate culture membranes (Whatman) and incubated in serum-free Neurobasal medium containing 2\% B27 supplement (Invitrogen), $100 \mathrm{U} / \mathrm{ml}$ penicillin, $100 \mu \mathrm{g} / \mathrm{ml}$ streptomycin, and $0.5 \%$ D-glucose at $37^{\circ} \mathrm{C}$ and $5 \% \mathrm{CO}_{2}$. For grafting experiments, microexplants (250 $\mu \mathrm{m}$ in diameter) of EGFP-donor littermates were dissected from brain slices that were coronally cut with a tissue chopper $(250 \mu \mathrm{m})$. The POA of the wild-type slices was removed before homotopic or heterotopic transplantation of the microexplants (see Fig. 2A). For blocking endogenous ephrin-B ligands, we added $5 \mu \mathrm{g} / \mathrm{ml}$ recombinant EphB3-Fc (R\&D Systems) to the medium, which was renewed after 1 div. The organotypic slice cultures were incubated for 2 div, and then fixed with $4 \%$ PFA in PBS for $2 \mathrm{~h}$ at room temperature.

siRNA and shRNA transfections. For siRNA transfections of dissociated cells, we used reverse lipofection applying Lipofectamine RNAiMAX (Invitrogen) according to the manufacturer's protocol. Cells prepared from the POA, VZ/SVZ, or IMZ of the MGE were plated on the stripes and incubated with 10 nM mouse EphA4 siRNA or 10 nm ephrinB3 siRNA, each containing a pool of three target-specific 20-25 nt siRNAs to knockdown gene expression (Santa Cruz Biotechnology) in combination with 10 nм Alexa 555-labeled RNA doublex (BLOCK-iT Alexa Fluor red fluorescent oligo; Invitrogen) to enable the visualization of the transfected interneurons. Transfection occurred for $5 \mathrm{~h}$ in antibiotics-free DMEM (Invitrogen) with 10\% FBS, $0.065 \%$ glucose, and $200 \mathrm{~mm} \mathrm{~L}$-glutamine at $37^{\circ} \mathrm{C}$ and $5 \% \mathrm{CO}_{2}$. Then the transfection medium was substituted with culture medium for dissociated neurons and cells were grown for 2 div at $37^{\circ} \mathrm{C}$ and $5 \% \mathrm{CO}_{2}$. For siRNA transfections in grafting experiments, we used the same approach and incubated the EGFP-expressing explants prepared from distinct domains in the transfection medium containing 10 nM siRNA for $5 \mathrm{~h}$ on a vertical shaker at $37^{\circ} \mathrm{C}$ and $5 \% \mathrm{CO}_{2}$. Explants were washed three times before transplantation to the wild-type slices in slice medium. For transfection of the POA domain in slice cultures with shRNA constructs, we performed focal electroporation using a Petri dish electrotrode (Nepagene). An agarose block (1\% agarose in Krebs' buffer) was placed on the Petri dish electrode, which serves as the positive pole. Then the polycarbonate culture membranes with the coronal slices were carefully plated on the Petri dish electrotrode. An agarose column (1\% agarose in Krebs' buffer, $0.5 \mathrm{~mm}$ in diameter, $2.5 \mathrm{~mm}$ in length) sticking to the upper electrode (negative pole) was loaded with $0.5 \mu \mathrm{l}$ of a GFPcontaining plasmid $(1 \mu \mathrm{g} / \mathrm{ml}$; Oligoengine). Then the electrode was placed directly on the POA domain of the brain slices and two square pulses (125 V, $15 \mathrm{~ms}$ with $500 \mathrm{~ms}$ interval) were applied. For transfection of the MGE domain, we performed ex utero electroporation according to Yozu et al. (2005). In brief, E14 hemispheres were dissected and embedded in $4 \%$ low-melt agarose. Then, $0.5 \mu \mathrm{l}$ of the GFP-containing plasmid $(1 \mu \mathrm{g} / \mathrm{ml})$ was pressure injected into the ventricular zone of the MGE, followed by two square pulses ( $100 \mathrm{~V}, 100 \mathrm{~ms}$ ) using $3 \mathrm{~mm}$ tweezers style electrodes and the BTX-ECM 830 electroporator (Harvard Apparatus). Then organotypic slices of the hemispheres were produced as described above.
In utero electroporation. The protocol for the in utero electroporation was approved by the Friedrich Schiller University (Jena, Germany). The protocol for intraventricular injection was modified according to Costa et al. (2009). Timed-pregnant E13.5 mice were treated preventively with $4 \mathrm{mg} / \mathrm{kg}$ Carprofen for $30 \mathrm{~min}$ before anesthetizing with a mixture of fentanyl $(0.05 \mathrm{mg} / \mathrm{kg})$, midazolam $(5 \mathrm{mg} / \mathrm{kg})$, and metedomidine $(0.5$ $\mathrm{mg} / \mathrm{kg}$ ). Deep anesthesia was verified by the absence of pain reflexes. The uterine horns were exposed after caesarean incision $(1 \mathrm{~cm})$, and $1 \mu \mathrm{l}$ of GFP-containing plasmid ( $1 \mu \mathrm{g} / \mathrm{ml}$; Optigene) with Fast Green $(2.5 \mathrm{mg} /$ $\mu \mathrm{l}$; Sigma-Aldrich) was injected through a pulled glass micropipette in the lateral ventricle that was visible under fiber optic lighting. Each embryo within its uterus was placed between $3 \mathrm{~mm}$ tweezers style electrodes with an angle of inclination of the electrode paddles with respect to the horizontal plane of the brain of $45^{\circ}$ to target the POA (Nepagene). Square electric pulses $(40 \mathrm{~V}, 100 \mathrm{~ms})$ were applied five times using a BTX-ECM 830 electroporator (Harvard Apparatus). Then embryos were quickly placed back into the abdominal cavity, which was rinsed with warmed $0.9 \% \mathrm{NaCl}$. The wall and skin of the abdominal cavity was sutured closed. Embryos were allowed to develop normally for $24 \mathrm{~h}$ before organotypic brain slices were prepared as described below for time-lapse video microscopy.

Verification of ephrinB3 and EphA4 silencing following shRNA and siRNA treatment. For validation of the ephrinB3 silencing by siRNA and shRNA treatment, NIH3T3 cell lines transfected with a retroviral vector, pLIG, containing the human ephrinB3 full-length cDNA and a G418 resistance were grown in DMEM/F-12 containing $10 \%$ heat-inactivated FBS, $1 \%$ penicillin/streptomycin, and $0.4 \%$ Geneticin G418. After cells reached $50 \%$ confluency, they were transfected with 200 pmol of control siRNA, ephrinB3 siRNA (Santa Cruz Biotechnology), or $0.4 \mu \mathrm{g} / \mathrm{ml} \mathrm{eph-}$ rinB3 shRNA (designed by Oligoengine) using Lipofectamine 2000 (Invitrogen) according to the manufacturer's protocol for $4 \mathrm{~h}$. After $24 \mathrm{~h}$, pictures were taken to determine the transfection efficiency. The RNA was isolated with Trizol (Roth) according to the manufacturer's instructions. For cDNA synthesis, the RevertAid Minus M-MuLV Reverse Transcriptase (Fermentas) was used $\left(42^{\circ} \mathrm{C}\right.$ for $\left.60 \mathrm{~min}\right)$. PCR against ephrinB3 (forward, GGGATATGGAAGCTTTGAGAC; reverse, GGTATCACCACCCACAACCAGC) and actin (forward, AGAGGGAAATCGTGCG; reverse, CAATAGTGATGACCTGGCCGT) was performed. To quantify the expression, ephrinB3 bands were normalized against actin.

To verify the knockdown of gene expression by EphA4 siRNA transfection, we transfected MGE-derived dissociated cells with EphA4 siRNA as described above and performed immunostaining using an antibody directed against EphA4 (rabbit anti-EphA4; 1:400; Santa Cruz Biotechnology). Pictures of cells were taken confocally as described below using the LSM 510 (Zeiss) with a $40 \times$ water-immersion objective (Zeiss CApochromat; NA 1.2). For quantitative analysis, the contours of transfected and nontransfected neurons positive for EphA4 were outlined and fluorescence intensities were measured using ImageJ. Fluorescence intensities of transfected cells were calculated relative to the intensities of nontransfected cells for each image.

Aggregation assay. The aggregation assay was modified after Gotz et al. (1996). In brief, dissociated cells of the VZ/SVZ and IMZ of the MGE of EGFP-expressing embryos and wild-type littermates were prepared as described above and collected in GBSS, which was then substituted by $\mathrm{Ca}^{2+} / \mathrm{Mg}^{2+}$-free HBSS with $1 \mathrm{~mm}$ EDTA (dissociation buffer). After several washings in dissociation buffer and incubation for $15 \mathrm{~min}$ in PBS with $1 \mathrm{nM}$ EDTA at $37^{\circ} \mathrm{C}$ and $5 \% \mathrm{CO}_{2}$, neuronal cells were dissociated mechanically. Cells were centrifuged for $5 \mathrm{~min}$ at $200 \times g$ and washed several times in culture medium (DMEM with 10\% FBS, 20 mM HEPES, $33 \mathrm{~mm}$ D-glucose, $0.11 \mathrm{~mm}$ L-glutamine and $100 \mathrm{U} / \mathrm{ml}$ penicillin, 100 $\mu \mathrm{g} / \mathrm{ml}$ streptomycin). Finally, cells were resuspended in $1 \mathrm{ml}$ of culture medium and cell number was determined. For the formation of aggregates, $1 \times 10^{6}$ cells $/ \mathrm{ml}$ of each fraction (wild-type-VZ/SVZ and EGFPIMZ, or vice versa) was used in a final volume of $400 \mu l$ per well in a 24 -well plate. For blocking endogenous ephrinB ligands in cells derived from the IMZ, we applied $20 \mu \mathrm{g} / \mathrm{ml}$ recombinant EphB1-Fc, while 20 $\mu \mathrm{g} / \mathrm{ml}$ recombinant ephrinA3-Fc was used for blocking endogenous EphA receptors in the VZ/SVZ fraction for $15 \mathrm{~min}$ at $37^{\circ} \mathrm{C}$ before aggre- 
gation. Aggregation was allowed for $6 \mathrm{~h}$ on a vertical shaker $(70 \mathrm{rpm})$ at $37^{\circ} \mathrm{C}$ and $5 \% \mathrm{CO}_{2}$. Cells were fixed by adding $40 \mu \mathrm{l}$ of $37 \%$ formalin directly to the medium for $15 \mathrm{~min}$ at room temperature. After centrifugation at $200 \times g$ for $15 \mathrm{~min}$, the majority of the medium with formalin was removed carefully and the cells were resuspended and embedded in Mowiol on slides for analysis.

Microscopy. In situ hybridizations and dissociated single cells were captured with a digital camera (Spot; Diagnostic Instruments) in combination with the Spot software and a Zeiss Axiovert S100 inverted microscope (Zeiss). Pictures were taken using a $5 \times$ objective for in situ hybridizations (Zeiss PlanNeofluar; NA 0.15), while the $20 \times$ objective (Zeiss PlanNeofluar; NA 0.5) was used in combination with fluorescence excitation to visualize the stripes or the respective fluorescence signal after immunohistochemistry. For quantification and documentation of the immunohistochemistry in cryosections, the organotypic slice cultures, and the aggregation assay, pictures were taken with a Zeiss laserscanning microscope (LSM) 510 and the LSM 510 or ZEN 2009 software (Zeiss) using a $10 \times$ objective (Zeiss PlanNeofluar; NA 0.6) or a $20 \times$ Plan-Apochromat objective (NA 0.75), an argon laser (wavelength, 488 $\mathrm{nm}$ ) with a $500-550 \mathrm{~nm}$ bandpass filter set and a helium-neon laser (wavelength, $543 \mathrm{~nm}$ ) in combination with an emission long-pass filter set $(560 \mathrm{~nm})$. For the analysis of EphA4 silencing, the Nrp-1 or Nrp-2 double labeling with calbindin, and the colocalization of Alexa 488labeled recombinant protein binding sites with immunohistochemical signals of pSrc, PY99, EphA4, and calbindin, pictures were taken with the Zeiss LSM 510 and the ZEN 2009 software (Zeiss) as described above, using a $40 \times$ immersion water objective (Zeiss; C-Apochromat; NA 1.2). The DAPI-stained nuclei were visualized using a tuneable two-photon titanium-sapphire laser (Mai-Thai; Spectra Physics) with a wavelength of $780 \mathrm{~nm}$ and a 435-485 nm bandpass filter set. The extraction of a single optical plane along the $x-y$-axis was performed with the ZEN 2009 software.

Time lapse. Time-lapse recordings of the migrating EGFP-neurons in organotypic slice cultures were captured with a Zeiss LSM 510 equipped with a $\mathrm{CO}_{2}$ - and temperature-controlled incubation chamber, using the ZEN 2009 software (Zeiss). Scans were acquired every $10 \mathrm{~min}$ with a $z$-stack of $10 \mu \mathrm{m}$, a $10 \times$ objective (Zeiss PlanNeofluar; NA 0.6), an argon laser $(488 \mathrm{~nm})$, and a bandpass of $500-550 \mathrm{~nm}$. Projections of the single scans were calculated with ZEN 2009 software (Zeiss) and exported as *jpg or *avi-files.

Quantitative analysis of in vitro assays. The distribution of the neurons in the stripe assays was determined using the cell counter plug-in of ImageJ (W. S. Rasband, National Institutes of Health, Bethesda, MD; http://rsb.info.nih.gov/ij/, 1997-2006), whereas only the location of the soma was taken into account. Total numbers of neurons on the alternating stripes were corrected according to the varying widths of the stripes. A paired $t$ test was used for statistical comparison using Microsoft Origin. Results (mean \pm SEM) are presented as a percentage; " $n$ " refers to the number of analyzed pictures. The analysis of the percentage of Nrp-1-, Nrp-2-, and calbindin-positive cells isolated from distinct domains of the basal telencephalon (mean \pm SEM) was also performed using the cell counter plug-in of ImageJ and " $n$ " refers to the number of analyzed pictures.

The distribution and distance from the explant of grafted EGFPexpressing cells in the wild-type slices was determined with ImageJ. The outline of the microexplant attached to the wild-type slice was measured, and the location of one-half of this range was set as reference point from which the distance of the migrated cells was determined. For the focal electroporation in the POA in slice cultures, the exact middle of the height of the POA (from the VZ to the subpial region) served as reference. For the quantification of the distribution of cells, the center of the POA or explant was connected with a point that marks one-half the height of the lateral ganglionic eminence (LGE) (from the VZ to the subpial region), splitting the slices in a deep and superficial compartment. Results are presented as percentage for the distribution and in micrometers for the distance of migrated cells (mean \pm SEM); " $n$ " refers to the number of analyzed slices. Student's $t$ test was used for statistical comparison using the Microsoft Origin software $\left({ }^{* *} p<0.0001,{ }^{* *} p>0.001,{ }^{*} p<0.05\right)$.
The migratory speed of EGFP cells in time-lapse recordings was analyzed with the LSM 510 software.

Quantitative analysis of the aggregation assay was performed with the Zeiss LSM 510 confocal microscope. Cellular clusters consisting of 10 or more cells were defined as an aggregate. According to Gotz et al. (1996), we considered aggregates as "pure," when only one to two cells were from different domains. When cells of distinct domains were arranged in separate clusters within the same aggregate, they were classified as "clustered," while intermingled cells were defined as "mixed" aggregates. Ortho-function applied to the $z$-stacks was used for correct classification. The numbers of pure, mixed, and clustered aggregates in different conditions were determined and the frequency of each category was calculated as the percentage of all aggregates (mean \pm SEM); “ $n$ " refers to the number of aggregates. Student's $t$ test was used for statistical comparison using the Microsoft Origin software $\left({ }^{* * *} p<0.0001,{ }^{* *} p>0.001,{ }^{*} p<0.05\right)$.

Quantitative analysis of the migratory streams. For the analysis of the direction of the leading processes of calbindin-labeled immature cortical interneurons, we exported single $z$-stacks of stitched images as ${ }^{*}$ jpg files to properly analyze the direction of the leading processes in the different planes. All pictures were edited in Photoshop CS3 for analysis, rotating each image to reach the same orientation with the POA directed to the left and the cortex to the right side. As indicated in Figure $6 \mathrm{~A}$, POA cells with leading processes with angles ranging from 0 to $90^{\circ}$ were defined as directed toward the deep migratory route, while angles of leading processes from 91 to $180^{\circ}$ were defined as directed toward the superficial migratory stream. For the quantification of the direction of leading processes in the MGE, we chose a region in the IMZ that excluded the superficial stream, which we named transition zone. The transition zone is indicated with the red square in Figure 6, $A$ and $K$. Due to the reduced cell density, the transition zone could be clearly identified with corresponding DAPI staining. The orientation of the leading process was determined by applying a vector from the nucleus to the tip of the leading process. The directions were categorized in four sectors with an angle of $45^{\circ}$ as illustrated in the black circle in Figure $6 \mathrm{~K}$. Sectors 1 and 3 represent vertical, and sectors 2 and 4 , horizontal orientations. The frequency of cells with horizontal and vertical orientation was determined as percentage (mean \pm SEM) of all cells analyzed. The numbers of analyzed brain sections is indicated as " $n$." Student's $t$ test was used for statistical comparison using the Microsoft Origin software $\left({ }^{* *} p<0.0001,{ }^{* *} p>0.001\right.$, ${ }^{\star} p<0.05$ )

For quantification of the relative fluorescence intensity of calbindinpositive cells in the MGE, an area of the MGE from the ventricle to the superficial migratory stream was analyzed with Image (Fig. 6A, white rectangle). All MGE sections were reduced to the same pixel height with Adobe Photoshop CS3 before. The highest fluorescence value was set to $100 \%$, and the lowest value to $0 \%$. The remaining fluorescence intensities were calculated in relation to these set values. ANOVA variance analysis was used for statistical comparison (SPSS software).

For quantification of the distance of invaded calbindin-expressing interneurons into the cortex, we measured the relative distance of immigrated interneurons in relation to the lateral cortical extension from the cortical striatal notch to the lateral medial border using ImageJ. The lateral extension of the cortex was set to $100 \%$, and the distance of the front of migrated cells was calculated relatively (mean \pm SEM).

\section{Results}

The complementary expression of EphA4 and ephrinB3 indicates that the deep and superficial migratory stream consist of distinct interneuron subsets

Cortical interneurons follow discrete routes during their longdistance migration from the basal telencephalon to the cortex: an outer subpial or superficial migratory stream and an inner or deep migratory stream along the SVZ at the peak of cortical interneuron migration at E14 (Corbin and Butt, 2011). In this study, we aimed to address the regulation of cortical interneuron segregation into the two migratory streams during the tangential migration. 


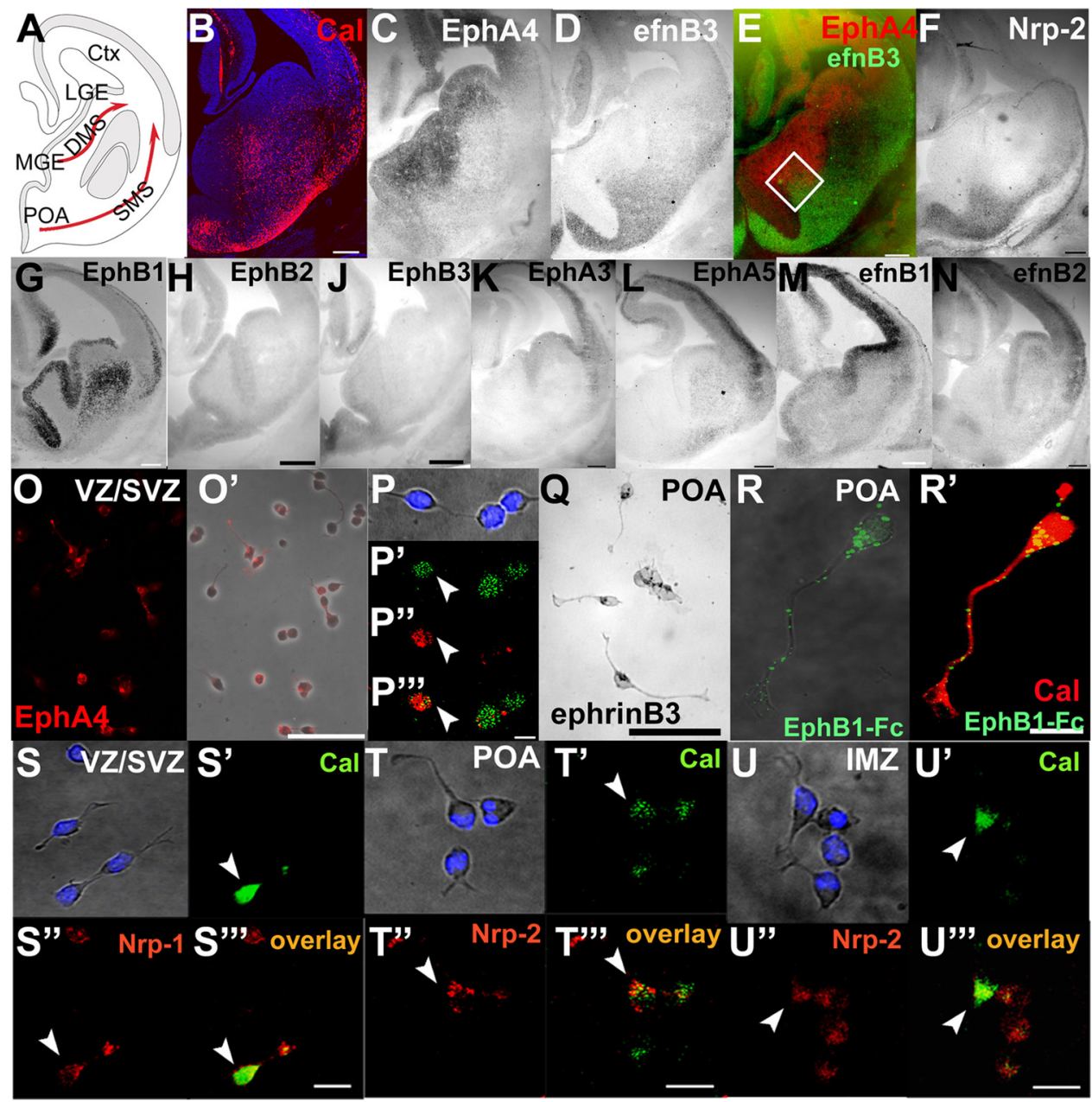

Figure 1. The deep and superficial migratory stream is differentially demarcated by EphA4 and ephrinB3 expression. $A$, Schematic illustration of the deep and superficial migratory stream and the anatomical regions in a hemisphere of an E14 coronal brain slice presented in $\boldsymbol{B}-\boldsymbol{N}$. $\boldsymbol{B}$, Overlay of DAPI and calbindin immunostaining of a coronal hemisphere (E14). $\boldsymbol{C}, \boldsymbol{D}$, In situ hybridization against EphA4 (C) and ephrinB3 (D) was performed on alternating E14 brain slices. $\boldsymbol{E}$, Pseudocolor overlay of $\boldsymbol{C}$ and $\boldsymbol{D}$ directly illustrates the complementary expression of EphA4 and ephrinB3. $\boldsymbol{F}$ - $\boldsymbol{N}$, In situ hybridizations using riboprobes against Nrp-2, EphB1, EphB2, EphB3, EphA3, EphA5, ephrinB1, and ephrinB2. O, EphA4 immunostaining of dissociated cells prepared from the VZ/SVZ of the MGE (E14 plus $1 \mathrm{div}) . \mathbf{O}^{\prime}$, Overlay of the EphA4 immunostaining shown in $\mathbf{0}$ with the respective phase-contrast microphotograph. Colabeling of EphA4 and calbindin in cells prepared from the VZ/SVZ (E14 plus 1 div) is shown in $\boldsymbol{P}-\boldsymbol{P}^{\prime \prime \prime}$ (arrowhead). Overlay of a transmitted light microphotograph with DAPI staining $(\boldsymbol{P})$, calbindin immunostaining $\left(\boldsymbol{P}^{\prime}\right)$, EphA4 immunostaining $\left(\boldsymbol{P}^{\prime \prime}\right)$, and overlay of calbindin (green) and EphA4 (red) $\left(\boldsymbol{P}^{\prime \prime \prime}\right)$. The arrow points to a double-labeled neuron. $\boldsymbol{Q}$, In situ hybridization in dissociated neurons prepared from the POA (E14 plus 1 div) using an ephrinB3 riboprobe. $\boldsymbol{R}, \boldsymbol{R}^{\prime}$, Calbindin-positive interneurons prepared from the POA exhibit Alexa 488-labeled EphB1-Fc binding sites, which label ephrinB ligands. $S-S^{\prime \prime \prime}$, Double labeling of calbindin and Nrp-1 in cells isolated from the VZ/SVZ of the MGE. $\boldsymbol{S}-\boldsymbol{S}^{\prime \prime \prime}$, Overlay of a transmitted light microphotograph with DAPI staining $(\boldsymbol{S})$, calbindin immunostaining $\left(\boldsymbol{S}^{\prime}\right)$, Nrp-1 immunostaining $\left(\boldsymbol{S}^{\prime \prime}\right)$, and overlay of calbindin (green) and Nrp-1 (red) $\left(\boldsymbol{S}^{\prime \prime \prime}\right)$. In $\boldsymbol{T}-\boldsymbol{T}^{\prime \prime}$ and $\boldsymbol{U}-\boldsymbol{U}^{\prime \prime \prime}$, double labeling of calbindin and Nrp-2 in cells isolated from the POA and IMZ, respectively. $\boldsymbol{T}, \boldsymbol{U}, 0$ verlay of a transmitted light microphotograph with DAPI staining. $\boldsymbol{T}^{\prime}, \boldsymbol{U}^{\prime}$, Calbindin immunostaining. $\boldsymbol{T}^{\prime \prime}, \boldsymbol{U}^{\prime \prime}$, Nrp-2 immunostaining. $\boldsymbol{T}^{\prime \prime}, \boldsymbol{U}^{\prime \prime \prime}$, Overlay of calbindin (green) and Nrp-2 (red). POA, Preoptic area; MGE, medial ganglionic eminence; LGE, lateral ganglionic eminence; Ctx, cortex; DMS, deep migratory stream; SMS, superficial migratory stream. Scale bars: $\boldsymbol{B}-\boldsymbol{N}, 200 \mu \mathrm{m} ; \mathbf{0}, \mathbf{O}^{\prime}, 100 \mu \mathrm{m} ; \boldsymbol{U}, 50 \mu \mathrm{m} ; \boldsymbol{P}-\boldsymbol{P}^{\prime \prime \prime}, \boldsymbol{R}^{\prime}$, $S^{\prime \prime \prime}-U^{\prime \prime \prime}, 10 \mu \mathrm{m}$.

To illustrate the routes of migrating interneurons, we performed immunohistochemistry at coronal brain sections at E14 using an antibody directed against calbindin, described to be an established marker for immature interneurons (Anderson et al., 1997; Polleux et al., 2002; Ang et al., 2003; Faux et al., 2010). Migrating interneurons were detected in the SVZ of the MGE and LGE, representing the deep route, as well as in the POA and SMS (Fig. $1 B$ ), which is consistent with what was found by others (Faux et al., 2010). Interneurons destined for the cortex, hippocampus, and striatum derive from the MGE and CGE (Anderson et al., 2001; Wonders and Anderson, 2006; Miyoshi et al., 2010), while the POA was described recently to generate interneurons for the cortex and amygdala (Gelman et al., 2009; Hirata et al., 2009).

Members of the Eph/ephrin system have been reported to regulate the tangential migration of cortical interneurons (Zim- mer et al., 2008; Rudolph et al., 2010). The ephrins and their receptors represent an important class of membrane-bound signaling molecules known to mediate repulsive interactions in various aspects of neuronal development (Klein, 2004; Pasquale, 2005).

Interestingly, we found a complementary expression pattern of EphA4 and ephrinB3 at E14, delineating the DMS and SMS, respectively (Fig. $1 C-E$ ). EphA4 is most prominently expressed in the SVZ of the MGE and LGE demarcating the DMS. Compared with the SVZ, EphA4 is weaker expressed in the VZ of the basal telencephalon in a medial to lateral gradient (Fig. 1C). In turn, ephrinB3 is strongly expressed in the POA and along the SMS (Fig. $1 D$ ), the latter representing the IMZ. The pseudocolor overlay of in situ hybridization experiments on alternating sections using probes against EphA4 and ephrinB3 illustrates that, in ad- 
dition to the complementary expression along the DMS and SMS, there is a partial overlap of EphA4 and ephrinB3 in the SVZ/IMZ of the MGE (Fig. $1 E$, white square).

Among all Eph receptors detected at the mRNA level using in situ hybridization at E14, EphA4 is most prominently expressed in the DMS of the basal telencephalon (Fig. 1C,G-L). EphA1 and EphA2 mRNA was not detected in the basal telencephalon (data not shown). EphA3 mRNA is exclusively expressed in the VZ of the lateral MGE and LGE of the subpallium, with only a slight signal in the SVZ of the LGE (Fig. $1 \mathrm{~K}$ ), while EphA5 is expressed in the developing striatum and the VZ of the LGE (Fig. $1 L$ ). None of the EphB receptors is expressed in the SVZ of the basal telencephalon, the DMS (Fig. 1G-J). The EphB1 riboprobe labels the VZ of the POA, MGE, and LGE in addition to the striatum (Fig. $1 G)$. EphB2 mRNA was detected in the VZ of the ganglionic eminences, including a weak signal in the POA (Fig. $1 H$ ). EphB3 was found to be expressed in a medial-to-lateral gradient in the VZ of the POA and the MGE (Fig. $1 J$ ).

Immunostaining against EphA4 at the single-cell level (E14 + 1 div) confirmed EphA4 expression in most of the cells isolated from the VZ/SVZ of the MGE (Fig. 1O,O'). To quantify the amount of EphA4 expression in interneurons from the DMS, we performed double labeling of VZ/SVZ cells of the MGE applying antibodies directed against calbindin and EphA4 (Fig. 1P-P'"). Our quantification revealed that $65.7 \pm 2.7 \%(n=226$ cells $)$ of the calbindin-expressing interneurons coexpress EphA4.

Due to the lack of reliable antibodies for immunocytochemistry, we performed in situ hybridization on dissociated cells prepared from the POA (E14 plus 1 div) using an ephrinB3 riboprobe (Fig. 1Q), which revealed that ephrinB3 mRNA was detected in $79.4 \pm 1.7 \%$ of the POA-derived cells ( $n=247$ cells). Moreover, we applied Alexa 488-labeled recombinant EphB1-Fc to dissociated POA cells (E14 plus 1 div) to validate ephrinB ligand expression at the protein level in the calbindin-expressing interneuron population of the POA (Fig. $1 R, R^{\prime}$ ). We found that $70.2 \pm 3.9 \%(n=308$ cells $)$ of the calbindin-positive POA cells exhibit ephrinB ligands. Furthermore, we applied EphB1-Fc to cells isolated from the IMZ of the MGE (E14 plus 1 div) to determine the number of ephrinB ligand-expressing interneurons migrating in the SMS. Approximately $70.2 \pm 5.4 \%$ of the IMZderived calbindin-positive interneurons exhibit EphB1-Fc binding sites $(n=293$ cells). Although less evident than ephrinB3, ephrinB1 is also expressed in the POA and SMS (Fig. 1M), while ephrinB2 is most abundant in the VZ of the LGE in the basal telencephalon (Fig. 1N). This indicates that the EphB1-Fc binding sites in the POA and IMZ refer to ephrinB3 ligands to a considerable extent. As a control experiment, we performed the EphB1-Fc binding study in combination with the calbindin immunostaining in dissociated cells prepared from whole basal telencephali of ephrinB3 homozygous knock-out embryos and wild-type littermates at E14 plus 1 div. While $62.9 \pm 3.7 \%(n=$ 729) of the wild-type cells exhibited EphB1-Fc binding sites, the recombinant protein bound only to $34.3 \pm 2.0 \%$ ( $n=1003$ cells $)$ of the ephrinB3 knock-out MGE-derived cells, which accounts for a reduction of at least $45.4 \%$ due to the lack of ephrinB3. The decreased EphB1-Fc binding to ephrinB3 knock-out cells confirms that EphB1-Fc interacts predominantly with ephrinB3 ligands in wild-type POA-derived interneurons.

The expression pattern of EphA4 along the DMS is reminiscent of what was shown for ErbB4, Cxcr7, and Nrp-1, identified as guidance receptors of MGE-derived cortical interneurons regulating their migration (Marín et al., 2001; Flames et al., 2004; Zimmer et al., 2010a; Wang et al., 2011). We already reported that
EphA4 expressed in calbindin-positive MGE-derived cortical interneurons is channeling their migration along the deep route by repellent interactions with ephrin $A 5$ and $-\mathrm{A} 3$, complementarily expressed in the $\mathrm{VZ}$ and striatal anlage, respectively (Zimmer et al., 2008; Rudolph et al., 2010). EphrinB3 expression in the basal telencephalon is very similar to what was found for Nrp-2 (Fig. $1 F$ ), a receptor of class III Semaphorins, reported to be expressed by MGE-derived cortical interneurons and to regulate their migration (Marín et al., 2001), demarcating the POA and the superficial migratory stream. Thus, in addition to the complementary expression of EphA4 and ephrinB3, the two receptors of class III semaphorins, Nrp-1 and Nrp-2, are also differentially expressed in the deep and superficial migratory route (Marín et al., 2001; Zimmer et al., 2010a). Using double-labeling experiments in dissociated cells at E14 plus 1 div, we confirmed that Nrp-1 was coexpressed with calbindin in interneurons prepared from the VZ/SVZ of the MGE (the DMS) (Fig. $1 S-S^{\prime \prime \prime}$ ), while Nrp-2 was coexpressed with calbindin in interneurons of the POA (Fig. 1T$\left.T^{\prime \prime}\right)$ and the IMZ (the SMS) (Fig. $\left.1 U-U^{\prime \prime \prime}\right)$. These data indicate that the two segregated migratory streams contain distinct interneuron subpopulations characterized by particular expression of guidance molecules that are born in different domains. As the complementary expression profiles fit with a model of mutual repulsion, we hypothesize that bidirectional repulsive EphA4ephrinB3 signaling triggers the segregation of interneurons in the deep and superficial migratory stream.

\section{Bidirectional ephrinB3-EphA4 signaling after cell-cell contact is involved in the segregation of interneurons in the DMS and SMS}

Next, we wanted to address the segregation of interneurons into the DMS and SMS. The data described above suggest that interneurons born in the proliferative zone of the MGE migrate deeply, while interneurons generated in the POA enter the SMS (Fig. 1A). To test whether deep and superficially migrating interneurons are restricted to their routes, we applied a set of in vitro assays. First, we performed heterotopic grafting experiments, in which EGFP-expressing explants prepared from the VZ/SVZ and the IMZ of the MGE were grafted to the POA domain of wild-type slices, which was removed before (Fig. $2 A-C$ ). In this experimental setup, grafted EGFP cells leaving the explants have the choice between the deep and superficial migratory compartment and the migration pattern was analyzed after 2 div. As illustrated in Figure 2, $B$ and $M$, the majority of EGFPexpressing neurons deriving from the VZ/SVZ of the MGE migrated mainly along the deep route. In addition, we found that the distance of migrating VZ/SVZ cells traversing the deep pathway was modestly yet significantly increased $(589 \pm 4.4 \mu \mathrm{m})$ compared with cells moving along the superficial route (560 \pm $7.3 \mu \mathrm{m} ;{ }^{* * *} p<0.0001$ ) (Fig. $2 N$ ). Time-lapse recordings of heterotopically grafted VZ/SVZ-EGFP explants illustrate the preferential migration in the deep compartment of the host slice (Fig. $2 D-G)$. Analysis of the migratory speed of EGFP cells in the deep and superficial compartments revealed a significant decline when VZ/SVZ-derived cells migrate superficially $(50.9 \pm 2.9 \mu \mathrm{m} / \mathrm{h}$; $n=40$ cells analyzed in three independent experiments) compared with neurons moving deeply $\left(69.4 \pm 2.1 \mu \mathrm{m} / \mathrm{h}\right.$; ${ }^{\star * *} p<$ $0.0001 ; n=59$ cells analyzed in four independent experiments). In addition to grafting experiments, we labeled VZ/SVZ cells of the MGE with a GFP-encoding construct applying ex utero electroporation in hemispheres at E14 (Fig. $2 \mathrm{H}$, arrowhead). Twenty-four hours after transfection, organotypic slice cultures were prepared and the migration was documented with time- 


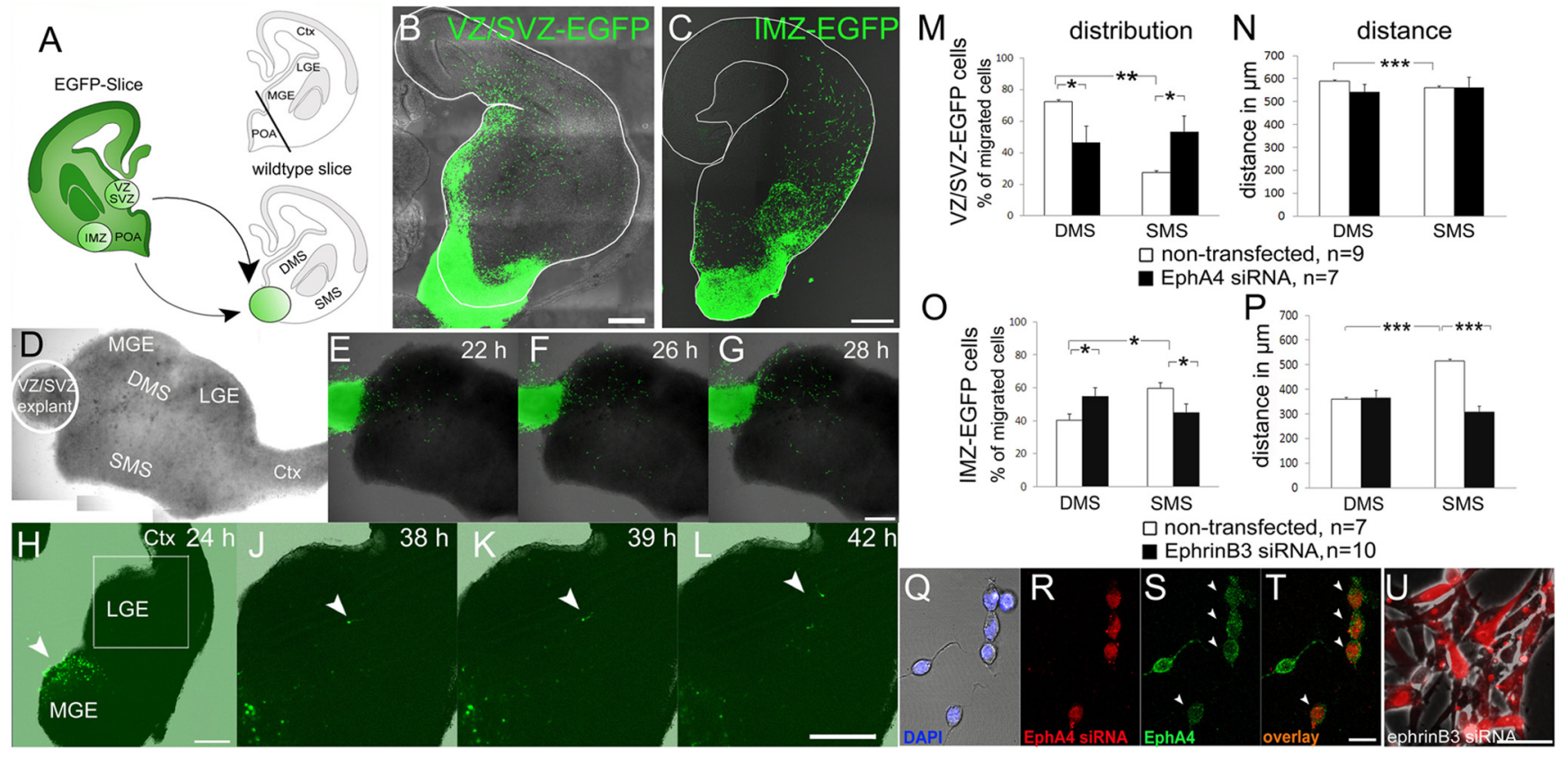

Figure 2. EphA4 and ephrinB3 are involved in the spatial segregation of deeply and superficially migrating interneurons. $A$, Schematic illustration of grafting experiments (presented in $B, C$, and D-G). $\boldsymbol{B}$, Heterotopic transplantation of an EGFP-expressing VZ/SVZ-derived microexplant to the POA of a wild-type slice. $\boldsymbol{C}$, Heterotopic transplantation of an EGFP-expressing IMZ-derived microexplant to the POA of a wild-type slice. D, Transmitted light microphotographs of a living organotypic brain slice (E14) $22 \mathrm{~h}$ after heterotopic transplantation of an EGFP-VZ/SVZ-derived explant to the POA of the host slice. E-G, Sequences of time-lapse recordings of grafted EGFP-VZ/SVZ cells after 22, 26, and $28 \mathrm{~h}$. $\boldsymbol{H}$, EGFP-transfected MGE cells $24 \mathrm{~h}$ after ex utero electroporation of hemispheres (E14). The site of transfection is indicated by the white arrowhead. $J-L$, Sequences of time-lapse recordings of ex utero EGFP-transfected MGE cells in organotypic slice cultures after 38 , 39 , and $42 \mathrm{~h}$ in vitro. The white arrowheads in $\boldsymbol{J}-\boldsymbol{L}$ label an MGE-derived cell migrating along the deep route. $\boldsymbol{M}, \boldsymbol{N}$, Analysis of the distribution $(\boldsymbol{M})$ and distance $(\boldsymbol{N})$ of nontransfected and EphA4-siRNA transfected EGFP-expressing VZ/SVZ-derived cells in wild-type slices $48 \mathrm{~h}$ after heterotopic transplantation to the POA. $\mathbf{0}, \boldsymbol{P}$, Analysis of the distribution (0) and distance $(\boldsymbol{P})$ of nontransfected and ephrinB3-siRNA transfected EGFP-expressing IMZ-derived cells in wild-type slices $48 \mathrm{~h}$ after heterotopic transplantation to the P0A. Error bars indicate SEM. *** $p<0.0001$, ${ }^{* *} p>0.001,{ }^{*} p<0.05$. Q-U, EphA4 siRNA reduces EphA4 expression in MGE-derived dissociated neurons. $\boldsymbol{Q}, 0$ verlay of a transmitted light microphotograph of dissociated MGE cells with DAPI staining. $\boldsymbol{R}$, EphA4 siRNA was coadministered with Alexa 555-conjugated control siRNA. S, Immunohistochemistry using an antibody directed against EphA4 resulted in reduced EphA4 staining intensity in cells transfected with EphA4 siRNA (overlay in $\boldsymbol{T}$ ). $\boldsymbol{U}$, EphrinB3-expressing NIH 3T3 fibroblasts cotransfected with Alexa 555-conjugated control siRNA and ephrinB3 siRNA. P0A, Preoptic area; MGE, medial ganglionic eminence; LGE, lateral ganglionic eminence; $C \mathrm{Ct}$, cortex; DMS, deep migratory stream; SMS, superficial migratory stream; VZ/SVZ, ventricular zone/subventricular zone; IMZ, intermediate zone. Scale bars: $\boldsymbol{B}, \boldsymbol{C}, \boldsymbol{G}, \boldsymbol{H}, \boldsymbol{L}, 200 \mu \mathrm{m} ; \boldsymbol{T}, 10 \mu \mathrm{m} ; \boldsymbol{U}, 50 \mu \mathrm{m}$.

lapse videomicroscopy. As illustrated in Figure $2 H-L$, GFPtransfected VZ/SVZ cells leave the MGE domain traversing the deep route to the cortex, which is consistent with what we observed in the grafting experiments.

In contrast, when we heterotopically grafted IMZ-EGFP explants to the POA of wild-type slices, the majority of migrating EGFP-neurons was observed in the superficial compartment (Fig. 2C,O). For this population, the mean distance from the explant was strongly decreased when migrating deeply $(360 \pm 6.4$ $\mu \mathrm{m})$ compared with neurons moving in the superficial path $\left(515 \pm 6.8 \mu \mathrm{m} ;{ }^{* *} p<0.0001\right)$ (Fig. $2 P$ ). Together, these data imply that EGFP cells prepared from the IMZ of the MGE preferentially migrate along the superficial migratory stream, while neurons derived from the VZ/SVZ prefer the deep route in the basal telencephalon.

Next, we applied a loss-of-function approach by RNA interference to assess the role of EphA4 and ephrinB3 in the guidance of interneurons following the distinct migratory streams. Silencing of EphA4 with target-specific siRNA was validated in dissociated MGE cells on the protein level by immunofluorescence. Immunostaining using an antibody directed against EphA4 was performed on MGE cells, either transfected with control or EphA4 siRNA, and the fluorescence intensity was determined. Compared with nontransfected and control-transfected MGE cells, EphA4 siRNA treatment reduced EphA4 expression by $32 \pm$ $2.9 \%$ ( $n=20$ analyzed frames of two independent experiments) (Fig. 2Q-T). Due to the lack of reliable antibodies for ephrinB3, we chose RT-PCR for validation of the efficiency of ephrinB3 silencing. EphrinB3-expressing NIH 3T3 fibroblasts were either transfected with control or ephrinB3 siRNA (Fig. 2U). Using RT-PCR, we quantitatively analyzed the expression of ephrinB3 mRNA normalized to the actin expression level and transfection efficiency. Compared with control-transfected fibroblasts, ephrinB3 mRNA was reduced by $50 \pm 6.6 \%(n=3$ independent experiments) by ephrinB3-specific siRNA.

To address the role of EphA4 in guiding interneurons of the deep route, we transfected explants isolated from the VZ/SVZ of EGFP-slices with EphA4 siRNA before heterotopical grafting to the POA of wild-type slices.

Examination of the migration pattern of VZ/SVZ-derived neurons revealed that the EphA4 knockdown abolished the preferential migration along the deep migratory stream as assessed for nontransfected cells, and led to an equal distribution of transfected cells in the host slices after $2 \operatorname{div}$ (Fig. $2 M$ ). In addition, the increased distance of nontransfected VZ/SVZ cells migrating along the deep compartment compared with cells moving superficially was also abolished by EphA4 silencing (Fig. 2N). EphrinB3 knockdown with siRNA in explants obtained from the IMZ in heterotopic transplantation experiments also resulted in an equal distribution after 2 div (Fig. 2O) and in a decreased distance of migrated IMZ-derived cells in the superficial migratory stream (Fig. $2 P$ ). Together, our observations indicate that repulsive EphA4-forward signaling mediates the guidance of MGE-derived neurons in the deep route. In contrast, re- 


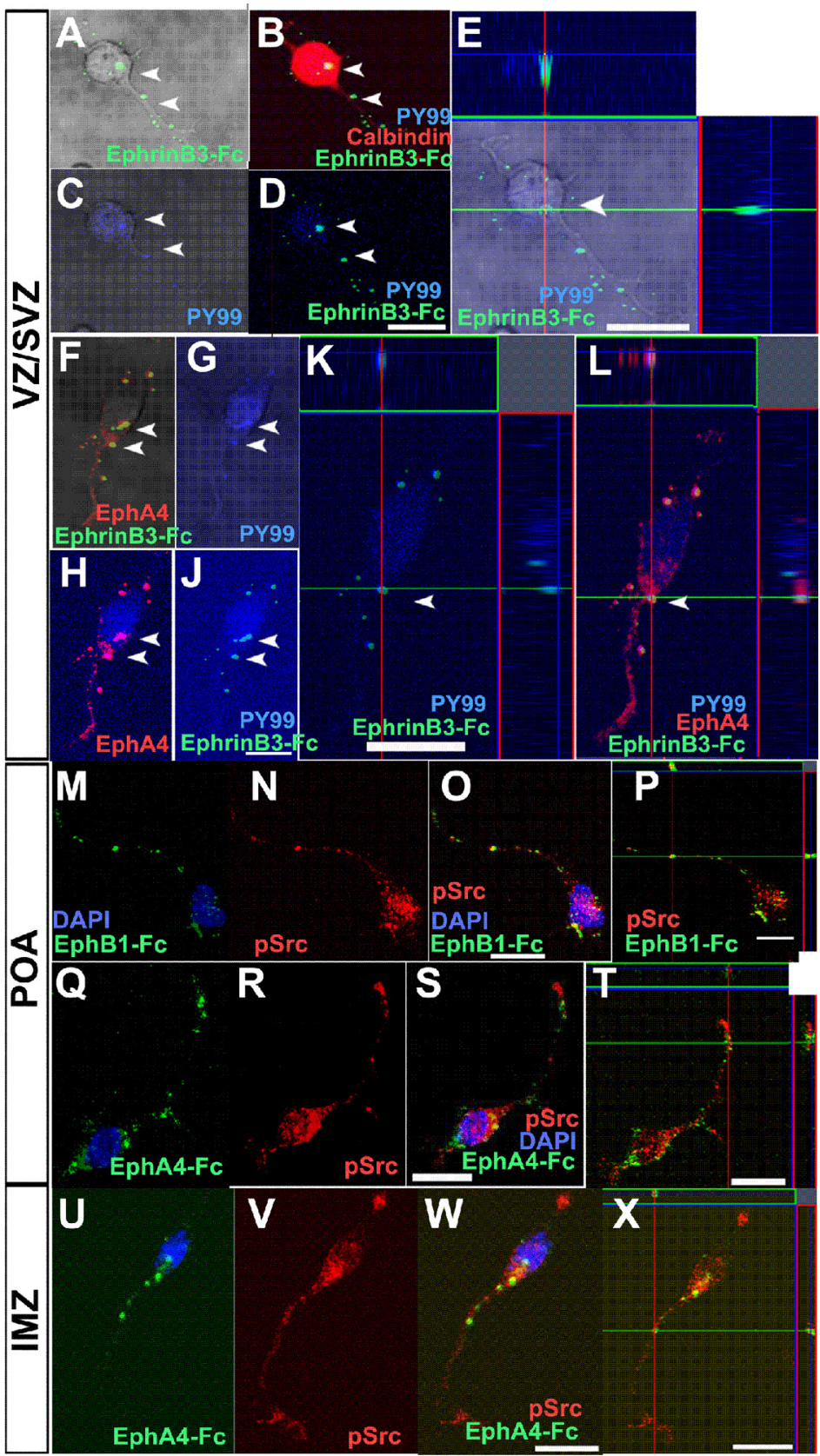

Figure 3. Binding studies revealed ephrinB3-induced phosphorylation of Eph receptors in cells derived from the VZ/SVZ of the MGE (forward signaling) and EphB1/EphA4-induced Src phosphorylation in POA- and IMZ-derived cells (reverse signaling). $\boldsymbol{A}-\boldsymbol{E}$, Triple immunostaining revealed that ephrinB3-Fc binding sites are colocalized with PY99 signals in calbindin-expressing cells prepared from the VZ/SVZ of the MGE, indicating activated Eph receptors. $A$, Overlay of the transmitted-light microphotograph with the ephrinB3-Fc binding sites. $\boldsymbol{B}$, Overlay of the calbindin and PY99 immunostaining with the ephrinB3-Fc binding sites. C, D, Overlay of the transmitted-light microphotograph with the PY99 immunostaining ( $\boldsymbol{C}$ and overlay of the PY99 immunostaining (blue) with the ephrinB3-Fc binding sites ( $g r e e n)(\boldsymbol{D})$. $\boldsymbol{E}$ illustrates $X$ and $Y$ line scans through a single optical plane for the colocalization of ephrinB3-Fc Alexa 488 (green) and PY99 (blue) in combination with transmitted light. $\boldsymbol{F}-\boldsymbol{L}$, EphrinB3-Fc binding (green) in VZ/SVZ cells is colocalized with the PY99 (blue) and EphA4 signal (red) indicating EphA4 receptor activation by ephrinB3.F, Overlay of the transmitted-light microphotograph with the ephrinB3-Fc binding sites (green) and EphA4 immunostaining (red). G, Overlay of the transmitted-light microphotograph with the PY 99 immunostaining. $\boldsymbol{H}, \boldsymbol{J}$ EphA4 immunostaining $(\boldsymbol{H})$ and overlay of PY99 (blue) immunostaining and ephrinB3-Fcsites (green) $(\boldsymbol{J})$. Killustrates an $X$ and $Y$ line scan through a single optical plane for the colocalization of ephrinB3-Fc Alexa 488 (green) and PY99 (blue), while $L$ illustrates the colocalization of ephrinB3-Fc Alexa 488 (green), EphA4 (red), and PY99 (blue). $\boldsymbol{M}-\boldsymbol{T}$, Alexa 488 marked EphB1-Fc (M-P) and EphA4-Fc binding sites (Q-T) are colabeled with phosphorylated Src (pSrc) in POA-derived single cells, suggesting activated ligands and reverse signaling. Overlay of EphB1-Fc and EphA4-Fc with DAPI staining is presented in $\boldsymbol{M}$ and $\boldsymbol{Q}$. The respective phospho-Src immunostaining is shown in $\boldsymbol{N}$ and $\boldsymbol{R}$. The overlay of phospho-Src and EphB1-Fc or EphA4-Fc is illustrated in $\mathbf{O}$ and $\mathbf{S}$, respectively. $\boldsymbol{U}-\boldsymbol{X}$, EphA4-Fc also induces Src activation in IMZ-derived cells. Overlay of EphA4- $\mathrm{F}$ with DAPI staining is presented in $\boldsymbol{U}$. The respective phospho-Srcimmunostaining is shown in $\boldsymbol{V}$. The overlay of phospho-Src (red) and EphA4-Fc binding (green) is illustrated in W. $\boldsymbol{P}, \boldsymbol{T}, \boldsymbol{X}$, Colocalization of Alexa 488-labeled EphB1-Fc or EphA4-Fc (green) with pSrc (red) is illustrated in $X$ and $Y$ line scans through a single optical plane for POA $(\boldsymbol{P}, \boldsymbol{T})$ and IMZ cells $(\boldsymbol{X})$. POA, Preoptic area; VZ/SVZ, ventricular zone/subventricular zone; IMZ, intermediate zone. Scale bars, $10 \mu \mathrm{m}$. verse repellent ephrinB3 signaling seems essential for interneurons moving superficially.

Next, we aimed to identify respective ligands that restrain interneuron subsets to their pathways. Based on the expression data and the functional assays described above, ephrinB3 represents the most promising ligand for repulsive EphA4-forward signaling involved in restricting deeply migrating interneurons. Conversely, EphA4 seems the most appropriate ligand for repulsive reverse ephrinB3 signaling in superficially migrating interneurons. In this scenario, both cell types, the EphA4-expressing interneurons of the DMS and the ephrinB3-expressing interneurons traversing the SMS, would be activated via EphA4-ephrinB3 binding, triggering bidirectional signaling.

To analyze whether ephrinB3 activates EphA4 receptors in MGE interneurons, we stimulated dissociated E14 cells prepared from the VZ/SVZ of the MGE with $5 \mu \mathrm{g} / \mathrm{ml}$ recombinant ephrinB3-Fc preclustered with an Alexa 488-anti-Fc antibody after 1 div for $2 \mathrm{~h}$, and performed subsequently double immunostaining, applying antibodies directed against calbindin and PY99, to label phosphorylated tyrosine residues (Fig. $3 A-E$ ). The phosphorylation of tyrosine residues of EphA4 receptors after ligand-induced activation was already shown in previous studies (Knöll and Drescher, 2004; Zimmer et al., 2007). As illustrated in Figure $3 A-D$, we found ephrinB3-Fc binding sites colocalized with PY99 signals in calbindinpositive cells deriving from the VZ/SVZ of the MGE. The colocalization of ephrinB3-Fc binding sites and PY99 is outlined in a $X$ and $Y$ line scan through a single optical plane (Fig. 3E). To directly show EphA4 receptor activation after ephrinB3-Fc binding, we performed a double immunostaining against EphA4 and PY99 after ephrinB3-Fc stimulation (Fig. $3 F-L$ ). As depicted in Figure 3, $K$ and $L$, the $X$ and $Y$ line scans through a single optical plane revealed colocalized signals for ephrinB3Fc, EphA4, and PY99. These data directly show an EphA4 receptor activation of cells deriving from the DMS of the MGE after ephrinB3-Fc ligand binding.

The Src family kinases (SFKs) have been described to be recruited to ephrinBcontaining lipid rafts and regulate EphB receptor-induced ephrinB phosphorylation and phosphotyrosine-mediated reverse signaling (Palmer et al., 2002). To examine whether Eph receptor-induced reverse signaling results in SFK activation at the receptor binding site upon ephrinB ligand activation, we stimulated dissoci- 
ated cells prepared from the POA and IMZ at E14 plus 1 div with clustered EphB1-Fc and EphA4-Fc before fixation, and performed an immunostaining with an antibody directed against activated $\mathrm{Src}$ (phosho-Src418) (Fig. 3M-X). Confocal imaging revealed a colocalization of phosphorylated Src and the Alexa 488-labeled EphB1-Fc binding sites in POA-derived cells, indicating ephrinB ligand activation (Fig. 3M-P). Phosphorylated Src was also found to be colocalized with the EphA4-Fc binding sites in POA- and IMZ-derived cells (Fig. 3Q-X). EphA4 is the only EphA receptor capable of interacting with ephrinB ligands in addition to A-ephrins (Martinez and Soriano, 2005). Quantification of EphA4-Fc binding in combination with calbindin immunostaining revealed that EphA4-Fc binds to $74 \pm 5.2 \%(n=215$ cells $)$ of the calbindin-positive POA-derived interneurons, indicating the expression of ephrinA and/or B ligands. Recombinant EphB1-Fc protein labels a similar number of calbindin-expressing interneurons of the POA $(70.2 \pm 3.7 \%$; $n=339$ cells $)$, interacting exclusively with ephrinB ligands. Thus, $<3.8 \%$ of the POA neurons bind EphA4 without possessing an ephrinB ligand. Together, these data show that EphA4 binds and activates $\mathrm{B}$ ligands in almost all POA cells, thereby inducing a reverse signaling in addition to its interaction with class A-ephrins.

To functionally test the potential effects of ephrinB3 and EphA4 acting as ligands on interneurons of the DMS and SMS, we performed stripe assays in which the cells prepared from the VZ/SVZ and IMZ of the MGE have the choice between recombinant ephrinB3-Fc and EphA4-Fc. After 2 div, we analyzed the distribution and found that VZ/SVZ cells preferentially grew on the EphA4-Fc-containing lanes avoiding the ephrinB3-Fc stripes (Fig. 4A,C). Conversely, EphA4-Fc exerted a repulsive response in neurons isolated from the IMZ that preferentially grew on the ephrinB3-Fccontaining lanes (Fig. 4B, C).

Next, we intended to determine whether ephrinB3-induced repulsion of deeply migrating interneurons is mediated by the EphA4 receptor. For this, we transfected cells prepared from the VZ/SVZ with EphA4 siRNA before plating on alternating stripes of ephrinB3-Fc and control protein $(\mathrm{Fc})$. After 2 div, the repulsion of ephrinB3-containing lanes observed for nontransfected cells was abolished after EphA4 silencing. The EphA4 receptor knockdown in VZ/SVZ-derived neurons resulted in an equal cell distribution on the alternating stripes of ephrinB3-Fc and control protein (Fig. 4D). This is consistent with our hypothesis that EphA4 forward signaling mediates the ephrinB3-induced repulsion in MGE-derived interneurons migrating deeply. Next, we introduced ephrinB3 siRNA in IMZderived dissociated neurons growing on alternating stripes of
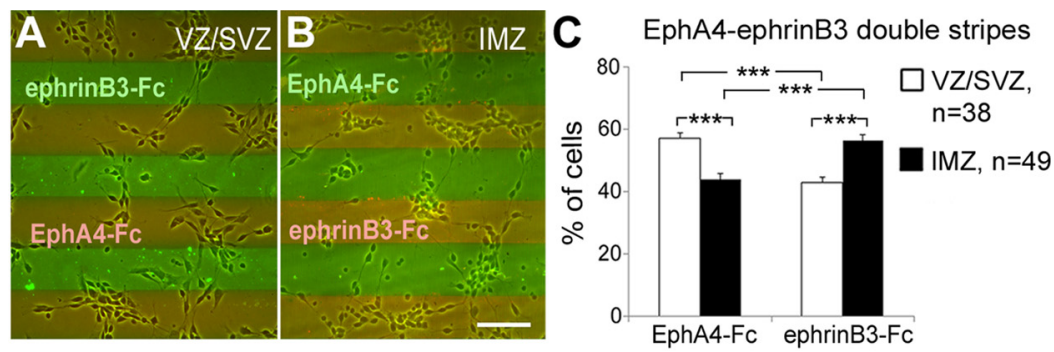

E
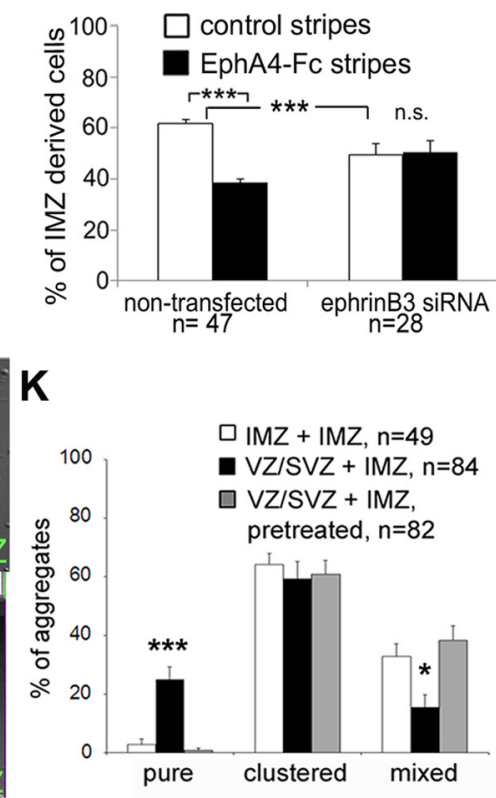

Figure 4. Stripe assays reveal that ephrinB3 triggers a repulsive response in VZ/SVZ cells mediated by the EphA4 receptor, while EphA4 acts as a repellent for cells prepared from the IMZ inducing ephrinB3 reverse signaling. $A$, Neurons prepared from the VZ/SVZ nontransfected and ephrinB3 siRNA-transfected MGE cells prepared from the IMZ on alternating stripes of EphA4-Fc and control lanes after $2 \mathrm{~d}$ in vitro. Selective adhesion of neurons isolated from the two migratory streams was analyzed with the short-term aggregation assay. $\boldsymbol{F}-\boldsymbol{K}$, The segregation of cells derived from the VZ/SVZ and IMZ in the aggregation assay depends on EphA4ephrinB3 signaling. $\boldsymbol{F}$, Pure aggregates containing only wild-type cells of the VZ/SVZ. G, Segregation of EGFP-IMZ and wild-type(control). J, Mixed aggregate obtained after pretreatment of wild-type VZ/SVZ cells with ephrinA3-Fc to block EphA receptors, and clustered, and mixed aggregates in different conditions. VZ/SVZ, Ventricular zone/subventricular zone; IMZ, intermediate zone. Scale bars: $\boldsymbol{A}, \boldsymbol{B}, 100 \mu \mathrm{m} ; \boldsymbol{F}-\boldsymbol{K}, 20 \mu \mathrm{m}$. Error bars indicate SEM. ${ }^{* * *} p<0.0001,{ }^{*} p<0.05$.

EphA4-Fc and control protein. After 2 div, nontransfected neurons avoided the EphA4-Fc-containing lanes, while downregulation of ephrinB3 completely abolished the EphA4-induced repulsion (Fig. $4 E$ ). These findings indicate that ephrinB3-reverse signaling mediates the repellent effect of EphA4 in interneurons migrating along the superficial route. Thus, in addition to its receptor function for cells in the SMS, ephrinB3 acts as a repellent cue for cells migrating along the DMS, mediated by EphA4 forward signaling.

To investigate the role of bidirectional ephrinB3-EphA4 signaling in the segregation of interneurons deriving from the two migratory routes after cell-cell contact, we performed a shortterm aggregation assay modified according to Gotz et al. (1996). The initial aggregation of dissociated cells in this assay was described to reflect the expression and function of cell surface signaling molecules, restricting cellular mixing to maintain positional information during forebrain development (Gotz et al., 
1996). Dissociated neurons were isolated from the VZ/SVZ of EGFP-expressing embryos, while cells of the IMZ were prepared from the respective wild-type littermates (or vice versa). Equal proportions of each cell fraction $\left(1 \times 10^{6}\right.$ cells/ml $)$ were mixed for aggregation. Cell aggregates were classified in three categories: pure (one cell type only), clustered or mixed (both cell types). Pure and clustered aggregates reflect a selective adhesion and segregation of the different cell populations (Fig. $4 F, G$ ), while mixed aggregates represent intermingled cells without adhesive preferences (Fig. $4 \mathrm{H}, \mathrm{J}$ ). As a control, we used cells deriving from the same region of EGFP-expressing and wild-type brains (Fig. $4 H$ ). Compared with this control, we found a significant increase in pure aggregates and a decreased number of mixed aggregates when cells from the VZ/SVZ and the IMZ were combined (Fig. $4 K)$. The number of clustered aggregates remained at the level of the positive control. The alterations in mixed and pure aggregates provide evidence that interneurons traversing the deep and superficial corridor possess distinct adhesive properties leading to a segregation of these distinct neuronal populations in the aggregation cultures, possibly mediated by the specific expression of cell surface molecules. To test whether ephrinB3-EphA4 signaling contributes to the selective adhesion of the interneuron subtypes, we preincubated dissociated cells prepared from the VZ/SVZ of the MGE with $20 \mu \mathrm{g} / \mathrm{ml}$ ephrinA3-Fc to block endogenous EphA4 receptors, and cells isolated from the IMZ with 20 $\mu \mathrm{g} / \mathrm{ml}$ EphB1-Fc, which binds endogenous ephrinB3 ligands, before aggregation. This treatment induced an increase in mixed and a decrease of pure aggregates similar to the level of the control (Fig. $4 J, K$ ). Together, these data support the hypothesis that bidirectional repulsive EphA4-ephrinB3 signaling after cell-cell contact regulates the segregation of the migratory streams in the basal telencephalon.

\section{The POA as a source of cortical interneurons contributes to neurons migrating superficially}

Next, we asked for the identity and origin of interneurons that traverse these distinct migratory routes. Cortical interneurons derive from the MGE, CGE, and the POA in a time-dependent manner (Corbin and Butt, 2011). At E14, the developmental stage used in our assays, the MGE and the POA mainly give rise to cortical interneurons (Miyoshi et al., 2007; Gelman et al., 2009; Corbin and Butt, 2011). The spatial expression of EphA4 in the SVZ of the MGE and LGE (Fig. 1C) and the results of the in vitro assays described above demonstrated that the MGE-derived interneurons enter the deep migratory route. This is consistent with previous studies demonstrating that homotopically transplanted EGFP-explants from the VZ/SVZ of the MGE to the MGE of host slices migrate along the DMS and avoid entering the SMS in the MGE (Zimmer et al., 2008, 2010a; Rudolph et al., 2010).

In contrast, in situ hybridization using a riboprobe against ephrinB3 resulted in a strong labeling of the POA and along the SMS (Fig. 1D). Likewise, the immunostaining against calbindin and Nrp-2 in situ hybridization as markers for interneurons also revealed an expression in the POA and the SMS (Fig. $1 B, F$ ). These expression profiles suggest that cells originating in the POA migrate mainly superficially, in contrast to MGE cells, which enter the DMS. To assess whether interneurons originating in the POA move superficially, we performed homotopic grafting experiments in which EGFP-POA explants were transplanted to the POA of wild-type slices, in analogy to the IMZ experiments presented above (Fig. $5 A, B$ ). Examination of the distribution of migrating EGFP cells in the deep and superficial compartments of the host slices after 2 div revealed that the majority of the POA cells enter the SMS (Fig. 5B,D). In addition, the distance of migrated POA cells from the explant in the subpial compartment was significantly increased compared with interneurons moving deeply (Fig. 5E).

We next aimed to assess the migration pattern of POAderived interneurons in vivo. It has been reported that single domains of basal telencephalon can be specifically electroporated in utero by ventricle targeted injection and directed electroporation at E13.5 with an inclination of the electrode paddles of $45^{\circ}$ with respect to the horizontal plane (Borrell et al., 2005). However, as previously also described by others (Gelman et al., 2009), we found that the site of transfection was not restricted to a single domain. In addition to the POA, other domains of the basal telencephalon were also targeted in most cases (data not shown). This complicates the analysis of the migration pattern of POAderived transfected cells after $2 \mathrm{~d}$ after transfection, as the site of origin of migrated cells could not be clearly identified. However, applying this transfection method at E13.5, it was at least possible to follow the migration of POA-transfected cells in organotypic slice cultures using time-lapse microscopy. Thus, embryos were killed $24 \mathrm{~h}$ after transfection and organotypic slice cultures were prepared in which the migration of POA-transfected cells was monitored. As illustrated in Figure 5F-J (asterisk), GFP-expressing POAderived interneurons started to migrate $24 \mathrm{~h}$ after transfection and entered the superficial migratory stream.

Next, we wanted to examine whether ephrinB3-EphA4 signaling is also required for the directional guidance of POA-derived cells. Therefore, we performed the functional studies described for the IMZ with POA-derived cells analogously. First, dissociated POA neurons transfected with ephrinB3 siRNA were plated on alternating stripes of EphA4-Fc and control lanes as described above (Fig. $5 N$ ). We found that nontransfected POA-derived cells avoided the EphA4 lanes, while ephrinB3 knockdown abolished the repulsion (Fig. 5O). To interfere with the ephrinB signaling in grafting experiments, we applied recombinant EphB3-Fc to slices in which a POA-derived explant of EGFPexpressing embryos was homotopically grafted to wild-type host slices (Fig. 5C). EphB3-Fc binds to endogenous ephrinB ligands, blocking these for interactions with endogenous Eph receptors. Analysis of the distribution of cells migrating in the dorsal and ventral compartment in the wild-type slices revealed that the preference for the superficial route was abolished by interfering with the ephrinB signaling (Fig. 5D,E).

Next, we aimed to silence ephrinB3 in POA-derived interneurons with RNA interference applying ephrinB3-specific shRNA and compare the migration pattern with control transfected POA cells after 2 div in analogy to the grafting experiments. To exclusively target the POA domain, we performed focal electroporation in organotypic brain slices. Due to its ventral position, we were able to transfect the POA without affecting other domains, with a plasmid containing ephrinB3-specific shRNA and GFP. A nontargeting shRNA-GFP construct served as control. The efficiency of the ephrinB3 shRNA was validated in ephrinB3expressing 3T3 NIH fibroblasts using RT-PCR. Compared with control-transfected fibroblasts and normalized to the transfection rate, we found a decrease of $74 \pm 9.4 \%(n=3$ independent experiments) in ephrinB3 expression. Analysis after 2 div revealed that the majority of control GFP-labeled POA cells migrated in ventral parts of the brain slices (Fig. $5 K, M$ ) consistent with our observations in the grafting experiments. In contrast, silencing of ephrinB3 in POA cells using focal electroporation resulted in an altered migration pattern. After 2 div, ephrinB3 shRNA transfected cells were less restricted to the superficial 

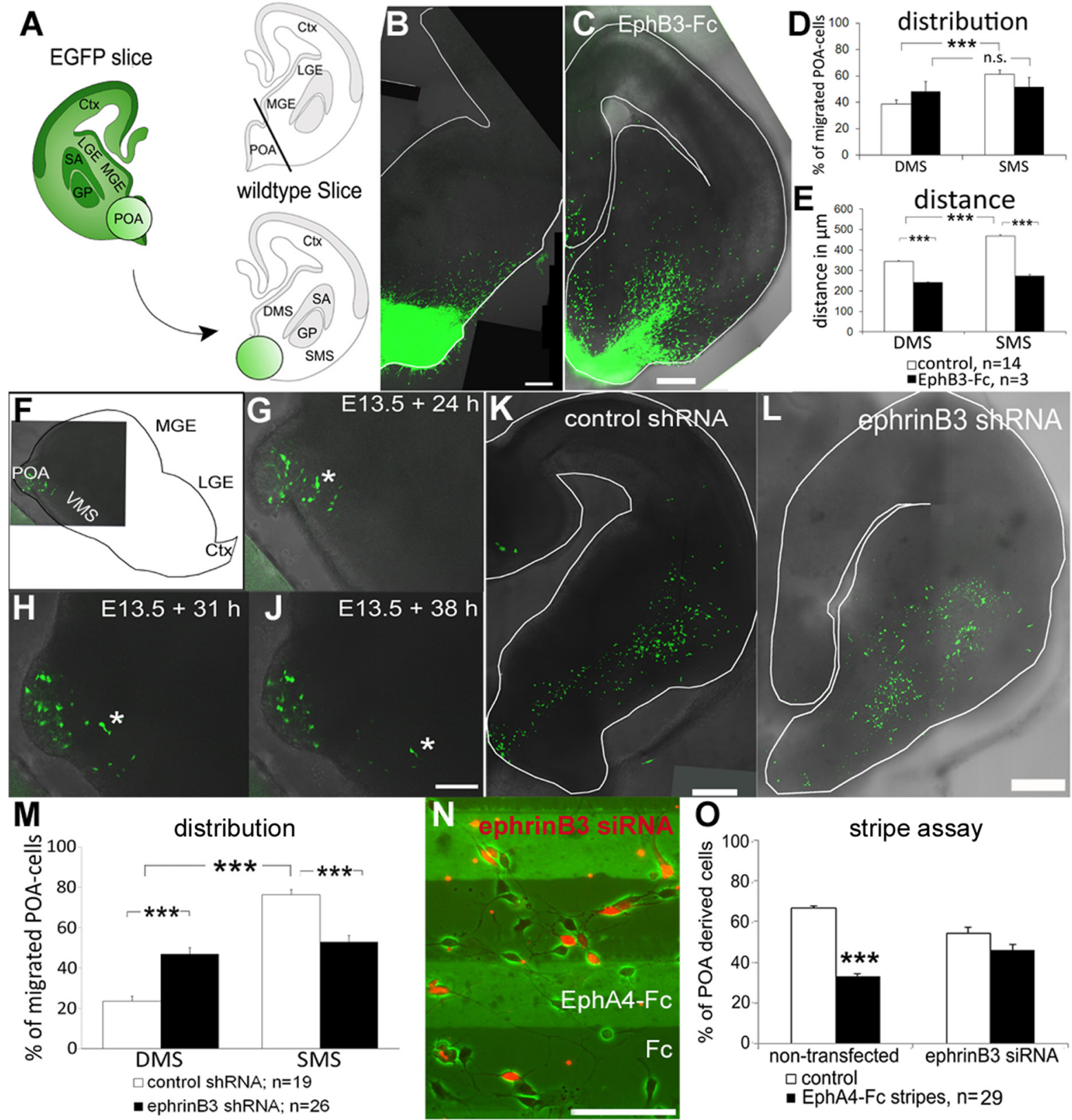

Figure 5. POA-derived interneurons give rise to the superficial migratory stream. $A$, Schematic illustration of homotopic grafting experiments illustrated in $B$ and $C . B, C$, Homotopic transplantation of E14 EGFP-POA microexplants to E14 wild-type slices under control conditions $(\boldsymbol{B})$ and with EphB3-Fc application ( $5 \mu \mathrm{g} / \mathrm{ml})$ after $2 \mathrm{~d}$ in vitro $(\boldsymbol{O})$. D, E, Quantitative analysis of the distribution (D) and distance (E) of migrated EGFP-POA cells in the wild-type slices at E14 plus $2 \mathrm{~d}$ in vitro under control conditions and with $5 \mu \mathrm{g} / \mathrm{ml}$ EphB3-Fc applied in the medium. F-J, In utero electroporation introducing a GFP-control construct in the POA of E13.5 embryos was performed, followed by time-lapse video capturing of migrating cells in organotypic brain slices $24 \mathrm{~h}$ after transfection. $K, \boldsymbol{L}$, Focal electroporation of a GFP-control construct $(\boldsymbol{K})$ and a construct containing ephrinB3 shRNA and GFP of POA cells in organotypic slices at E14 after $2 \mathrm{~d}$ in vitro $\boldsymbol{( L )}$. $\boldsymbol{M}$, Quantitative analysis of the distribution of control-transfected and ephrinB3shRNA transfected POA cells in organotypic slices at E14 plus $2 \mathrm{~d}$ in vitro. N, EphrinB3 siRNA transfected (red) and untransfected POA cells on alternating stripes of Alexa 488-labeled EphA4-F c stripes (green) and unlabeled control lanes at E14 plus 2 div. 0, Quantitative analysis of the distribution of control-transfected and ephrinB3-siRNA-transfected dissociated POA-derived cells in alternating stripes of control and EphA4-Fc stripes after 2 d in vitro. POA, Preoptic area; MGE, medial ganglionic eminence; LGE, lateral ganglionic eminence; Ctx, cortex; DMS, deep migratory stream; SMS, superficial migratory stream; SA, striatal anlage; GP, globus pallidus. Scale bars: $\boldsymbol{B}, \boldsymbol{C}, \boldsymbol{K}, \boldsymbol{L}, 200 \mu \mathrm{m} ; \mathbf{G}-J, 100 \mu \mathrm{m} ; \boldsymbol{N}, 50 \mu \mathrm{m}$. Error bars indicate SEM. ${ }^{* * *} p<0.0001$.

route in the host slices (Fig. $5 L, M$ ). Together, these data demonstrate that POA-derived cells give rise to the superficial migratory stream, and reverse ephrinB3 signaling induced by EphA4 is involved in the restriction of POA-derived interneurons to the superficial migratory route.

Disorganized migratory interneurons in the POA and MGE of mutant mice

The in vitro data presented so far indicate that bidirectional EphA4-ephrinB3 signaling is involved in the segregation of mi- gratory routes, which we aimed to verify in vivo. Due to the redundancy and high promiscuity of interactions of the Eph/ephrin system, the deletion of an individual gene of the Eph/ephrin system mostly leads to only subtle albeit highly reproducible abnormalities (Uziel et al., 2002, 2008; Guellmar et al., 2009; Zimmer et al., 2010b) or even to no detectable phenotypes (Feldheim et al., 2000; Mendes et al., 2006). In addition, the complete knockdown of a single gene can lead to adaptive or compensatory changes in other genes. For example, $20 \%$ of the Eph/ephrin genes expressed in the cortex were found to be upregulated in ephrinA5 mutant 
mice (Peuckert et al., 2008). Although heterozygous ephrinB3/ EphA4 knock-out mice (further designated as efnB3/EphA4 ${ }^{+/-}$) do not exhibit a complete loss of function, the reduced expression levels of both genes might help reveal the effects of bidirectional ephrinB3/EphA4 signaling in interneuron migration. In addition, we expect less compensatory mechanisms in the heterozygous mutants. Thus, we analyzed the migration pattern of cortical interneurons in heterozygous efnB3/EphA $4^{+/-}$double-mutant mice as well as homozygous ephrinB3 single knock-out embryos ( $\mathrm{efnB}^{-/-}$) at E14. We performed immunostaining against calbindin at E14, to label MGE- and POA-derived immature interneurons. For analysis, we included only sections along the anterior-posterior axis, which contained the POA, MGE, and LGE.

As described above, in the wild types, calbindin-expressing neurons were found in the MGE and along the deep migratory route, as well as in the POA and the superficial route (Fig. $6 \mathrm{~B}$ ). Although the overall pattern of the two migratory streams seems basically intact in the efnB3/EphA $4^{+/-}$and efnB3 ${ }^{-/-}$mutant mice (Fig. $6 C, D$ ), calbindin-positive interneurons in the POA were disorganized and less restricted to the superficial route compared with the wild types, as indicated by the arrows in Figure $6 B-D$ (magnified in Fig. 6E-G). We detected an increased number of ectopic cells in the $\mathrm{VZ}$ of the POA with leading processes directed toward the DMS in both, the efnB3/EphA4 ${ }^{+/-}$and efnB3 ${ }^{-/-}$knock-out embryos. For the quantitative analysis of the orientation of interneurons in the POA, we determined the angle of the vector from the cell body to the tip of the leading process with respect to the vertical axis of the POA (parallel to the midline) as illustrated in Figure $6 \mathrm{~A}$. Leading processes with angles within the range of $0-90^{\circ}$ were defined as directed toward the DMS, while processes with angles between 91 and $180^{\circ}$ were defined as superficially oriented. Our analysis revealed that the number of POA-derived interneurons that oriented their leading processes toward the DMS increased from $29.4 \pm 3.5 \%$ in wildtype brains ( $n=16$ sections of 5 brains) to $43.3 \pm 2.8 \%$ in efnB3 ${ }^{-/-}$brains $\left(n=9\right.$ sections of 2 brains; $\left.{ }^{*} p<0.05\right)$ and even to $50.4 \pm 3.4 \%$ in efnB3/EphA4 ${ }^{+/-}$mutant brains $(n=14 \mathrm{sec}-$ tions of 7 brains; $\left.{ }^{* *} p<0.0001\right)$. This indicates a reduced restriction of POA cells toward the SMS in the mutants.

In addition to misdirected POA interneurons, a reduced segregation was observed in the IMZ of the MGE, which we named transition zone between the dorsal and ventral migratory stream (illustrated in Fig. $6 \mathrm{~A}, \mathrm{~K}$ ). The transition zone is characterized by lower densities of DAPI-stained nuclei (Fig. $6 A$, red square) and by overlapping ephrinB3 and EphA4 expression (Fig. $1 E$ ). The wild-type littermates exhibit a low density of calbindin-positive interneurons in this region (Fig. $6 \mathrm{H}$, white square), while an augmented number of calbindin-expressing interneurons was identified in the efnB3/EphA $4^{+/-}$mutants (Fig. 6I, white square). For quantification, we measured relative fluorescence intensities from the $\mathrm{VZ}$ to the superficial migratory stream of the MGE as indicated by the white box in Figure $6 A$, setting the highest value to $100 \%$, the lowest value to $0 \%$. The normalized plots revealed an increased fluorescence intensity in the transition zone in the efnB3/EphA4 ${ }^{+/-}$embryos (Fig. $6 J$ ), indicating a higher number and a diminished segregation of calbindinexpressing interneurons in the MGE. ANOVA variance analysis revealed a significant difference between the plots of the wildtype ( $n=29$ sections of 7 independent brains) and the efnB3/ EphA $4^{+/-}$knock-out mice $(n=10$ sections of 5 independent brains; $\left.F_{(1,38)}=3.48 ;{ }^{* *} p<0.0001\right)$. Although we observed an increased number of calbindin-expressing interneurons in the transition zone of the efnB3 $3^{-/-}$compared with the wild types, the effect was less profound than the efnB3/EphA4 ${ }^{+/-}$mutants (Fig. $6 L-N$ ). The relative fluorescence intensity measured in efnB3 ${ }^{-/-}$brain sections was not significantly different from control animals (data not shown). This could be due to redundant expression of ephrinB1 in the POA as well as potential compensatory molecular mechanisms in the efnB3 ${ }^{-1-}$ single knock-out mice as discussed above. Moreover, the indirect quantification by measuring relative fluorescence intensities could be not sensitive enough to reveal subtle differences in the efnB3 ${ }^{-1-}$ mice. Therefore, we performed another type of quantification, directly analyzing the orientation of the leading processes of calbindin-expressing interneurons in the transition zone of the MGE. For this, we classified the direction of the leading processes into two groups, horizontally and vertically oriented interneurons. Cells with a vector from the nucleus to the tip of the leading process oriented within the $45^{\circ}$ angle of sectors 1 or 3 (toward the DMS or SMS, respectively; indicated by the circle of Fig. $6 \mathrm{~K}$ ) were grouped as vertically directed. In turn, if the orientation of the leading process was within the range of the $45^{\circ}$ angle of sectors 2 or 4 (toward the cortex or POA, respectively), cells were considered as horizontally oriented. As shown in Figure $6 L-O$, our analysis revealed an increased number of interneurons with leading processes directed vertically in both types of mutant mice compared with the wild type. In control brains, $\sim 55.8 \pm 2.4 \%$ of interneurons exhibit a vertical orientation of their leading process ( $n=33$ sections of 8 wild-type brains) (Fig. $6 \mathrm{~L}, O$ ), which increased significantly to $73.4 \pm 2.3 \%$ in the efnB3/EphA4 $4^{+/-}$ mutant mice ( $n=18$ sections of 6 efnB3/EphA $4^{+/-}$brains) (Fig. $6 N, P)$ and to $70 \pm 2.3 \%$ in the efnB3 ${ }^{-1-}$ embryos $(n=9$ sections of 2 brains) (Fig. $6 \mathrm{~N}, \mathrm{O}$ ). The increase in number and the vertical orientation of interneurons in the transition zone of the knockout mice indicates a reduced segregation of interneurons into the deep and superficial migratory stream.

To investigate whether the increased intermingling of interneurons between the DMS and SMS in the basal telencephalon affects the migration into the cortex, we analyzed the migratory streams in the SVZ/IMZ of the cortex in the mutant mice. As indicated in Figure $6 P-R$, compared with the mutant mice, interneurons migrated over longer distances in the wild-type cortex, which points to a delayed invasion of interneurons in the cortices of the mutants at E14. We measured the distance of immigrated interneurons in relation to the lateral cortical extension from the cortical striatal notch to the lateral medial border. We found that, in wild types, calbindin-positive interneurons invaded $47.1 \pm 1.8 \%(n=20$ analyzed sections of 5 brains $)$ of the lateral cortical extension, while this distance was reduced to $36.7 \pm 2 \%\left(n=14\right.$ analyzed sections of 6 brains; $\left.{ }^{* * *} p<0.0001\right)$ in the efnB3/EphA4 ${ }^{+/-}$mutants (Fig. 6P-Q). This is consistent to what we found for the efnB3 ${ }^{-1-}$ single mutants; the mean distance was decreased to $36.9 \pm 2.5 \%(n=10$ sections of 3 brains) (Fig. 6R) $\left({ }^{* *} p<0.001\right)$. This delay could result from the disorganized migration in the basal telencephalon.

In contrast to calbindin-expressing immature interneurons, the number and distribution of postmitotic Olig-2-expressing oligodendrocyte precursors remained unchanged in the efnB3/ EphA4 ${ }^{+/-}$mice, indicating that the effects are specific to migrating interneurons (data not shown).

Together, these results suggest misrouted POA- and MGEderived interneurons in the efnB3/EphA4 heterozygous and efnB3 homozygous knock-out mice and a reduced segregation of the two migratory streams. These findings are in line with what we observed in vitro and support our model of the involvement of bidirectional EphA4-ephrinB3 signaling in the segregation of 


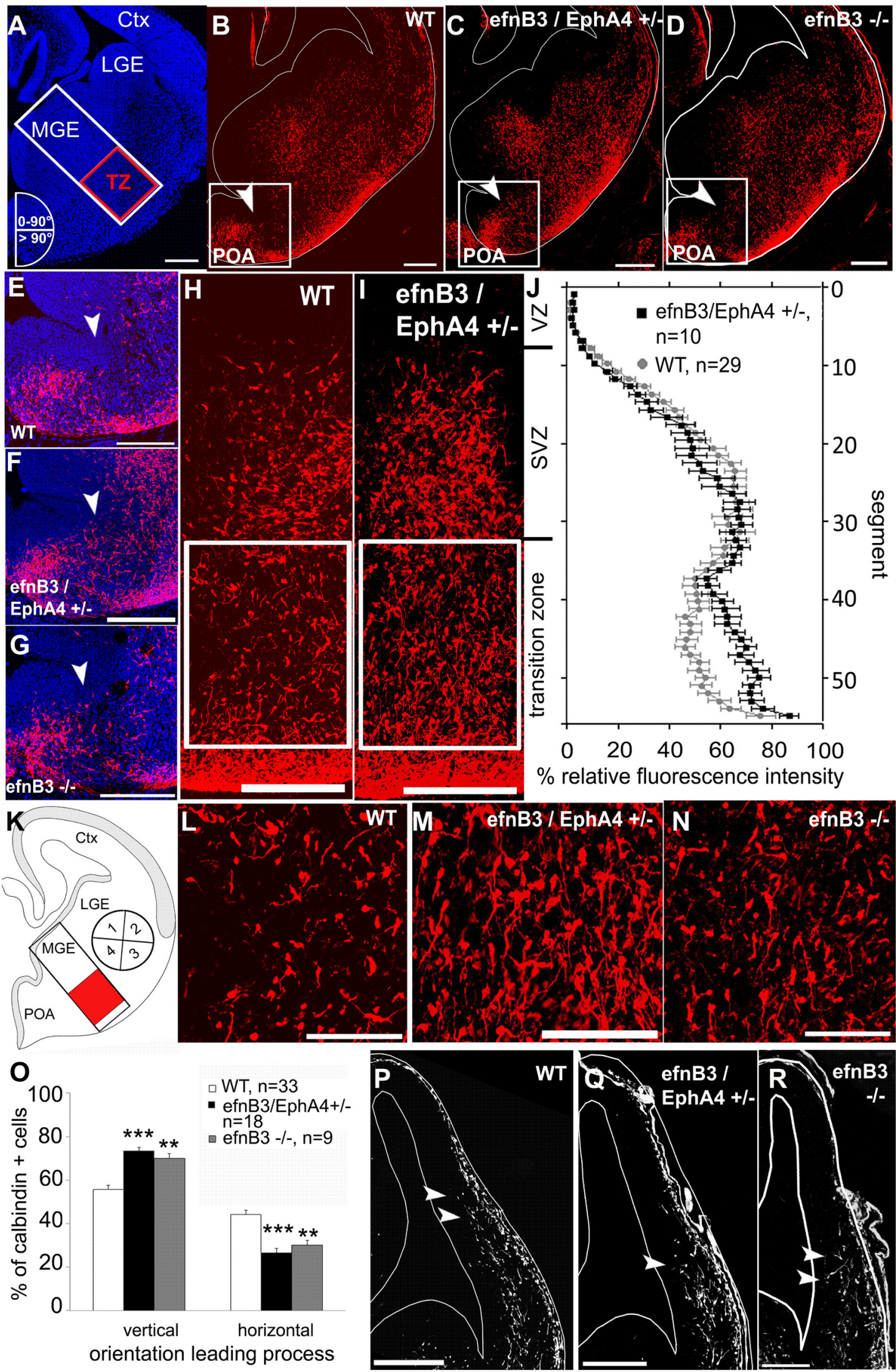

Figure 6. Segregation of POA- and MGE-derived cells is affected in heterozygous efnB3/EphA4 double mutants. A, DAPI staining of a coronally sectioned hemisphere of a wild-type E14 brain. $\boldsymbol{B}$, Calbindin immunostaining of a coronally sectioned hemisphere of a wild-type E14 brain. C, $\boldsymbol{D}$, Calbindin immunostaining of a heterozygous efnB3/EphA4a mutant brain ( $\boldsymbol{C}$ ) and of a homozygous efnB3 knock-out coronal section atE14 (D). The white arrowheads in $\boldsymbol{B}-\boldsymbol{D}$ indicate ectopic cells in the deep aspect of the P0A in mutant mice that were absent in the wild types, as (Figurelegend continues.) 

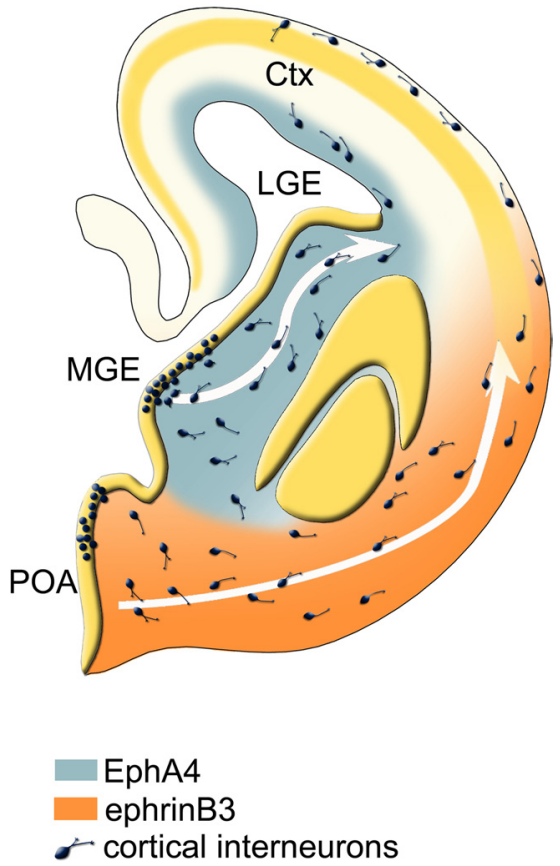

Figure 7. Model for the segregation of POA- and MGE-derived interneurons into the superficial and deep migratory stream. MGE-derived interneurons express EphA4 and migrate along the deep route, while interneurons generated in the POA express ephrinB3 and traverse the superficial pathway. EphA4 acts as a ligand for ephrin $\mathrm{B} 3$ and induces repulsive reverse signaling in interneurons generated in the POA. In addition to its receptor function, ephrinB3 binds to EphA4 and induces a repellent response in MGE-derived interneurons. Thus, cell-cell contactmediated repulsive bidirectional ephrinB3/EphA4 signaling in the transition zone of the MGE restricts intermingling of different subsets of interneurons and is involved in sorting these interneuron subtypes in segregated migratory streams.

calbindin-expressing interneurons deriving from the MGE and POA into the deep and superficial migratory route in the basal telencephalon (Fig. 7).

\section{Discussion}

In the developing forebrain, transcriptional factor-based cellautonomous regulation and environmental cues orchestrate region- and time-specific programs of differentiation and migra-

$\leftarrow$

(Figure legend continued.) magnified in $\boldsymbol{E}-\boldsymbol{G}$. The white rectangle drawn into the MGE in $\boldsymbol{A}$, is magnified in $\boldsymbol{H}$, for the wild type, and in $\boldsymbol{I}$, an equivalent region from the efnB3/EphA4 ${ }^{+/-}$ brain, and was used to plot the profile of the fluorescence intensity. $J$, The mean relative fluorescence intensity is significantly increased in the transition zone of the mutant mice (illustrated by the red squares in $\boldsymbol{A}$ and $\boldsymbol{K}$ and the white squares in $\boldsymbol{H}, \boldsymbol{I})$, representing an increased number of calbindin-positive interneurons in that region (ANOVA, $F_{(1,38)}=3.48$; ${ }^{* * *} p<0.0001$ ). $\mathbf{L}-\mathbf{0}$, The orientation of leading processes of interneurons in the transition zone of wild types $(\boldsymbol{L})$, the efnB3/EphA4 ${ }^{+/-}(\boldsymbol{M})$, and efnB3 ${ }^{-/-}(\boldsymbol{N})$ brain sections was quantitatively analyzed $(\boldsymbol{P})$. For the quantification of the orientation of the leading processes, the estimated vector from the nucleus to the tip of the leading process for each cell was categorized in four sectors with an angle of $45^{\circ}$ as illustrated in the circle in $\boldsymbol{K}$. Sectors 1 and 3 represent vertical; and sectors 2 and 4 , horizontal orientations. 0 , The frequency of cells with horizontal and vertical orientation was determined as percentage (mean \pm SEM) of all cells analyzed and revealed a significant increase in vertically oriented interneurons in the efnB3/EphA4 ${ }^{+/-}\left({ }^{* * *} p<0.0001\right)$ as well as in the homozygous single knock-outs efnB3 ${ }^{-1-}\left({ }^{* *} p<0.001\right) . \boldsymbol{P}-\boldsymbol{R}$, Magnification of the cortices of wild-type $(\boldsymbol{P})$, the efnB3/EphA4 ${ }^{+/-}(\boldsymbol{Q})$, and the efnB3 ${ }^{-/-}(\boldsymbol{R})$ coronal brain sections stained with an antibody directed against calbindin after photoconversion, to illustrate the distance of interneurons invading the cortex at E14, which was reduced in the knock-out mice. The white arrowheads in $\boldsymbol{P}-\boldsymbol{R}$ indicate the front of migrated interneurons. POA, Preoptic area; $M G E$, medial ganglionic eminence; $L G E$, lateral ganglionic eminence; DMS, deep migratory stream; SMS, superficial migratory stream. Scale bars: $\boldsymbol{B}-\mathbf{G}, 200 \mu \mathrm{m} ; \boldsymbol{H}, \boldsymbol{I}, \boldsymbol{L}-\boldsymbol{N}, \boldsymbol{P}-\boldsymbol{R}, 100 \mu \mathrm{m}$. tion of interneuron precursors to ensure the correct number and variety of neurochemically defined interneuron subtypes. Interneurons born in the MGE, CGE, and POA give rise to discrete subsets that are suggested to be intrinsically programmed to particular phenotypes mediated by a specific combinatorial code of transcription factors (Butt et al., 2005; Flames et al., 2007; Miyoshi et al., 2007, 2010; Gelman et al., 2009). What remains unclear is whether interneuron precursors generated in separated domains follow specific migratory pathways due to the characteristic expression of guidance cues as part of their internal programming. Cortical interneurons migrate along defined routes from the basal telencephalon to the cortex, traversing an inner or deep migratory stream along the SVZ and an outer or superficial route along the mantle zone or subpial region. Our in vitro and in vivo data suggest a segregation of interneurons into the two migratory streams dependent on their site of generation.

Interneurons generated in different domains traverse distinct migratory routes in the basal telencephalon

Applying several approaches, we found that interneurons deriving from the POA and MGE are characterized by distinct expression of guidance receptors and migrate along segregated routes. We showed that interneurons generated in the VZ/SVZ of the MGE traverse the DMS and express EphA4. In contrast, interneurons prepared from the POA migrate superficially and express ephrinB3.

The preferential migration of MGE-derived interneurons along the deep migratory stream is in concordance to what we found with homotopic grafting experiments reported in previous studies (Zimmer et al., 2008, 2010a; Rudolph et al., 2010), as well as with the migration pattern shown by other groups, with DiIlabeled (Ghanem et al., 2007) or GFP-transfected MGE cells (Flames et al., 2004). EphA4, expressed in the SVZ of the ganglionic eminences, was recently reported to be involved in channeling MGE-derived interneurons into the deep migratory route by repulsive interactions with ephrinA5 and ephrinA3 expressed in the $\mathrm{VZ}$ and developing striatum, respectively (Zimmer et al., 2008; Rudolph et al., 2010). The expression pattern of EphA4 in the SVZ of the MGE and LGE overlaps with the spatial expression of ErbB4 and Cxcr7, two guidance receptors of MGE-derived cortical interneurons mediating attractive effects of neuregulins and CXCR12 during their tangential migration through the DMS (Flames et al., 2004; Wang et al., 2011).

In contrast to MGE-derived neurons, we found that POAderived interneurons migrate superficially in the basal telencephalon. The POA was recently described to generate cortical interneurons as well as interneurons destined for the amygdala (Gelman et al., 2009; Hirata et al., 2009). In the study of Hirata et al. (2009), the authors exploited Dbx1-lacZ mice to follow the fate of the POA interneurons and identified a superficial migration, which they termed as the POA-amygdala migratory stream. In this study, we demonstrate that at least a portion of cells deriving from the POA and the superficial migratory route (IMZ) express the cortical interneuron marker Nrp-2 in addition to ephrinB3 and calbindin (Marín et al., 2001; Nobrega-Pereira et al., 2008). This further supports the finding that, in addition to interneurons destined for the amygdala, the POA domain also generates cortical interneurons traversing the SMS.

Our observations indicate that distinct subsets of interneurons originating in specific domains give rise to DMS and SMS, which are characterized by a particular expression of guidance receptors. In addition to EphA4 and ephrinB3, class III semaphorin receptors Nrp-1 and Nrp-2 expressed by cortical in- 
terneurons (Marín et al., 2001; Nobrega-Pereira et al., 2008) also exhibit differential expression profiles in the ganglionic eminences. Nrp-1 mRNA demarcates the deep route (Zimmer et al., 2010a), while Nrp-2 was detected superficially (Fig. $1 F$ ). The hypothesis that Nrp-1- and Nrp-2-positive interneurons represent distinct interneuron subsets is supported by a study of Le et al. (2007) that provided evidence that Dlx1/Dlx2 specifically repress the transcription of Nrp-2 but not Nrp-1. In agreement with this finding, Dlx1 and Dlx2 expression was reported in the SVZ of the eminences coincident with Nrp-1, but complementary to what we found for Nrp-2 (Long et al., 2009b; Wang et al., 2011). The homeoproteins Dlx1 and Dlx2, identified to mediate the neuronal cell fate in Olig2 precursors of the basal telencephalon (Petryniak et al., 2007), were reported as crucial players in forebrain GABAergic neuron differentiation, migration, and survival (Anderson et al., 1997; Cobos et al., 2005, 2007; Long et al., 2007, 2009a). Ghanem et al. (2007) reported that distinct subtypes of cortical interneurons use different combinations of Dlx1/2 enhancers from the time of specification to adulthood. The authors argued that the Dlx1/2 enhancers, UER 2 and I12b, were differentially expressed in particular domains of the basal telencephalon and in distinct cell populations of the inner and outer migratory stream close to the corticostriatal boundary. These data are consistent with our findings that specific interneuron subtypes traverse the deep and superficial migratory streams in the basal telencephalon.

\section{Bidirectional ephrinB3/EphA4 signaling is involved in the segregation of the interneurons in the deep and superficial migratory routes in the basal telencephalon}

One unique feature of Eph/Ephrin signaling is that ephrins as well as Eph receptors act as receptors and ligands, enabling forward and reverse signaling. Bidirectional Eph/ephrin signaling was frequently reported as an essential mechanism in neurodevelopmental processes like synapse formation, axonal guidance, and neuronal migration (for review, see Davy and Soriano, 2005; Egea and Klein, 2007; Klein, 2009). Our results indicate that bidirectional EphA4-ephrinB3 signaling dictates cell contact-mediated segregation of distinct interneuron subsets into the deep and superficial migratory stream. In the heterozygous efnB3/EphA4 double-mutant mice as well as in homozygous efnB3 knock-out mice, a reduced segregation was observed in the POA and in the MGE domain.

EphA4 is the only EphA receptor known to interact with B ligands in addition to class A ephrins reviewed by Martinez and Soriano (2005). We found that the repulsive response of MGEderived interneurons induced by ephrinB3 was reduced after EphA4 downregulation in vitro. This implies that ephrinB3, which is complementarily expressed to EphA4 in the POA and along the superficial migratory stream, acts as a repellent signal for interneurons traversing the DMS. Repulsive EphA4 forward signaling was already reported in various aspects of nervous system development (Drescher et al., 1995; Dottori et al., 1998; Wahl et al., 2000; Uziel et al., 2002; Knöll and Drescher, 2004; Zimmer et al., 2007, 2008; Rudolph et al., 2010). Moreover, we found that EphA4 in turn induces repulsive ephrinB3 reverse signaling in POA-derived cells, restricting this subpopulation to the SMS. EphrinB activation in POA-derived cells was accompanied by Src activation, similar to what was reported in other systems (Palmer et al., 2002).

Our study implies the participation of bidirectional interactions, including EphA4 forward and ephrinB3 reverse signaling in sorting of interneuron subsets into the segregated migratory streams. Homozygous efnB3 knock-out mice show an increase in misdirected interneurons in the POA and MGE, where the segregation into the two migratory routes occurs, which was even more prominent in heterozygous efnB3/EphA4 double mutants. In support of our model, bidirectional but not unidirectional EphA4/EphB2 and ephrinB2 signaling is required to restrict intermingling of distinct rhombomeric cell populations during hindbrain development (Mellitzer et al., 1999; Xu et al., 1999). Unidirectional signaling through Eph receptors or ephrinB ligand was not sufficient to induce cell sorting of adjacent cell populations and resulted in cell intermingling across segmental boundaries. Furthermore, bidirectional Eph/ephrin-reverse signaling was described to regulate the compartmentalized organization of neurons within the striatum (Janis et al., 1999; Passante et al., 2008). However, the segregation of migratory streams was not completely abolished, neither in the efnB3 ${ }^{-/-}$nor the efnB3/ EphA $4^{+/-}$mutant mice. In addition to potential compensatory mechanisms in the efnB3 single knock-out and the incomplete knockdown in the heterozygous double mutants, other guidance systems could be also involved in this process.

In conclusion, these data support the model that different subsets of interneurons are already prespecified when they start to migrate. The subtype-specific expression of guidance receptors, mediating the migration in distinct corridors could be regulated by the specific combinatorial expression of transcription factors that is suggested to determine the spatially distinct cohorts of interneuron subtypes (Flames et al., 2007; Long et al., 2009b). However, the transcriptional link between particular transcription factor characteristics of MGE- and POA-derived interneurons and EphA4/ephrinB3 expression remains to be elucidated. Thus, uncovering the interplay of transcriptional programs and environmental guidance cues in interneuron migration might be important to identify critical pathophysiological events that lead to interneuronopathies, which describe human diseases or a set of neurological symptoms that arise from impairments of tangential GABAergic interneuron migration.

\section{References}

Anderson SA, Eisenstat DD, Shi L, Rubenstein JL (1997) Interneuron migration from basal forebrain to neocortex: dependence on Dlx genes. Science 278:474-476.

Anderson SA, Marín O, Horn C, Jennings K, Rubenstein JL (2001) Distinct cortical migrations from the medial and lateral ganglionic eminences. Development 128:353-363.

Ang ES Jr, Haydar TF, Gluncic V, Rakic P (2003) Four-dimensional migratory coordinates of GABAergic interneurons in the developing mouse cortex. J Neurosci 23:5805-5815.

Borrell V, Yoshimura Y, Callaway EM (2005) Targeted gene delivery to telencephalic inhibitory neurons by directional in utero electroporation. J Neurosci Methods 143:151-158.

Butt SJ, Fuccillo M, Nery S, Noctor S, Kriegstein A, Corbin JG, Fishell G (2005) The temporal and spatial origins of cortical interneurons predict their physiological subtype. Neuron 48:591-604.

Cobos I, Calcagnotto ME, Vilaythong AJ, Thwin MT, Noebels JL, Baraban SC, Rubenstein JL (2005) Mice lacking Dlxl show subtype-specific loss of interneurons, reduced inhibition and epilepsy. Nat Neurosci 8:1059-1068.

Cobos I, Borello U, Rubenstein JL (2007) Dlx transcription factors promote migration through repression of axon and dendrite growth. Neuron 54:873-888.

Corbin JG, Butt SJ (2011) Developmental mechanisms for the generation of telencephalic interneurons. Dev Neurobiol 71:710-732.

Costa MR, Bucholz O, Schroeder T, Gotz M (2009) Late origin of gliarestricted progenitors in the developing mouse cerebral cortex. Cereb Cortex 19 [Suppl 1]:i135-i143.

Davy A, Soriano P (2005) Ephrin signaling in vivo: look both ways. Dev Dyn 232:1-10. 
Dottori M, Hartley L, Galea M, Paxinos G, Polizzotto M, Kilpatrick T, Bartlett PF, Murphy M, Köntgen F, Boyd AW (1998) EphA4 (Sek1) receptor tyrosine kinase is required for the development of the corticospinal tract. Proc Natl Acad Sci U S A 95:13248-13253.

Drescher U, Kremoser C, Handwerker C, Löschinger J, Noda M, Bonhoeffer F (1995) In vitro guidance of retinal ganglion cell axons by RAGS, a 25 $\mathrm{kDa}$ tectal protein related to ligands for Eph receptor tyrosine kinases. Cell 82:359-370.

Egea J, Klein R (2007) Bidirectional Eph-ephrin signaling during axon guidance. Trends Cell Biol 17:230-238.

Faux C, Rakic S, Andrews W, Yanagawa Y, Obata K, Parnavelas JG (2010) Differential gene expression in migrating cortical interneurons during mouse forebrain development. J Comp Neurol 518:1232-1248.

Feldheim DA, Kim YI, Bergemann AD, Frisén J, Barbacid M, Flanagan JG (2000) Genetic analysis of ephrin-A2 and ephrin-A5 shows their requirement in multiple aspects of retinocollicular mapping. Neuron 25: 563-574.

Flames N, Long JE, Garratt AN, Fischer TM, Gassmann M, Birchmeier C, Lai C, Rubenstein JL, Marín O (2004) Short- and long-range attraction of cortical GABAergic interneurons by neuregulin-1. Neuron 44:251-261.

Flames N, Pla R, Gelman DM, Rubenstein JL, Puelles L, Marín O (2007) Delineation of multiple subpallial progenitor domains by the combinatorial expression of transcriptional codes. J Neurosci 27:9682-9695.

Gebhardt C, Bastmeyer M, Weth F (2008) Cold Spring Harbor meeting: axon guidance and neuronal plasticity. Cold Spring Harbor, NY: Cold Spring Harbor Laboratory.

Gelman DM, Martini FJ, Nóbrega-Pereira S, Pierani A, Kessaris N, Marín O (2009) The embryonic preoptic area is a novel source of cortical GABAergic interneurons. J Neurosci 29:9380-9389.

Ghanem N, Yu M, Long J, Hatch G, Rubenstein JL, Ekker M (2007) Distinct cis-regulatory elements from the Dlx1/Dlx2 locus mark different progenitor cell populations in the ganglionic eminences and different subtypes of adult cortical interneurons. J Neurosci 27:5012-5022.

Gotz M, Wizenmann A, Reinhardt S, Lumsden A, Price J (1996) Selective adhesion of cells from different telencephalic regions. Neuron 16:551-564.

Guellmar A, Rudolph J, Bolz J (2009) Structural alterations of spiny stellate cells in the somatosensory cortex in ephrin-A5-deficient mice. J Comp Neurol 517:645-654.

Hernández-Miranda LR, Parnavelas JG, Chiara F (2010) Molecules and mechanisms involved in the generation and migration of cortical interneurons. ASN Neuro 2:e00031.

Hirata T, Li P, Lanuza GM, Cocas LA, Huntsman MM, Corbin JG (2009) Identification of distinct telencephalic progenitor pools for neuronal diversity in the amygdala. Nat Neurosci 12:141-149.

Ikeda K, Ikeda K, Iritani S, Ueno H, Niizato K (2004) Distribution of neuropeptide $\mathrm{Y}$ interneurons in the dorsal prefrontal cortex of schizophrenia. Prog Neuropsychopharmacol Biol Psychiatry 28:379-383.

Janis LS, Cassidy RM, Kromer LF (1999) Ephrin-A binding and EphA receptor expression delineate the matrix compartment of the striatum. J Neurosci 19:4962-4971.

Klein R (2004) Eph/ephrin signaling in morphogenesis, neural development and plasticity. Curr Opin Cell Biol 16:580-589.

Klein R (2009) Bidirectional modulation of synaptic functions by Eph/ephrin signaling. Nat Neurosci 12:15-20.

Knöll B, Drescher U (2004) Src family kinases are involved in EphA receptor-mediated retinal axon guidance. J Neurosci 24:6248-6257.

Kullander K, Croll SD, Zimmer M, Pan L, McClain J, Hughes V, Zabski S, DeChiara TM, Klein R, Yancopoulos GD, Gale NW (2001) Ephrin-B3 is the midline barrier that prevents corticospinal tract axons from recrossing, allowing for unilateral motor control. Genes Dev 15:877-888.

Le TN, Du G, Fonseca M, Zhou QP, Wigle JT, Eisenstat DD (2007) Dlx homeobox genes promote cortical interneuron migration from the basal forebrain by direct repression of the semaphorin receptor neuropilin-2. J Biol Chem 282:19071-19081.

Leighton PA, Mitchell KJ, Goodrich LV, Lu X, Pinson K, Scherz P, Skarnes WC, Tessier-Lavigne M (2001) Defining brain wiring patterns and mechanisms through gene trapping in mice. Nature 410:174-179.

Levitt P, Eagleson KL, Powell EM (2004) Regulation of neocortical interneuron development and the implications for neurodevelopmental disorders. Trends Neurosci 27:400-406.
Lewis DA, Levitt P (2002) Schizophrenia as a disorder of neurodevelopment. Annu Rev Neurosci 25:409-432.

Long JE, Garel S, Alvarez-Dolado M, Yoshikawa K, Osumi N, Alvarez-Buylla A, Rubenstein JL (2007) Dlx-dependent and -independent regulation of olfactory bulb interneuron differentiation. J Neurosci 27:3230-3243.

Long JE, Swan C, Liang WS, Cobos I, Potter GB, Rubenstein JL (2009a) Dlx1\&2 and Mash1 transcription factors control striatal patterning and differentiation through parallel and overlapping pathways. J Comp Neurol 512:556-572.

Long JE, Cobos I, Potter GB, Rubenstein JL (2009b) Dlx1\&2 and Mash1 transcription factors control MGE and CGE patterning and differentiation through parallel and overlapping pathways. Cereb Cortex 19 [Suppl 1]:i96-i106.

Marín O, Rubenstein JL (2001) A long, remarkable journey: tangential migration in the telencephalon. Nat Rev Neurosci 2:780-790.

Marín O, Yaron A, Bagri A, Tessier-Lavigne M, Rubenstein JL (2001) Sorting of striatal and cortical interneurons regulated by semaphorinneuropilin interactions. Science 293:872-875.

Martínez A, Soriano E (2005) Functions of ephrin/Eph interactions in the development of the nervous system: emphasis on the hippocampal system. Brain Res Brain Res Rev 49:211-226.

Mellitzer G, Xu Q, Wilkinson DG (1999) Eph receptors and ephrins restrict cell intermingling and communication. Nature 400:77-81.

Mendes SW, Henkemeyer M, Liebl DJ (2006) Multiple Eph receptors and B-class ephrins regulate midline crossing of corpus callosum fibers in the developing mouse forebrain. J Neurosci 26:882-892.

Miyoshi G, Butt SJ, Takebayashi H, Fishell G (2007) Physiologically distinct temporal cohorts of cortical interneurons arise from telencephalic Olig2expressing precursors. J Neurosci 27:7786-7798.

Miyoshi G, Hjerling-Leffler J, Karayannis T, Sousa VH, Butt SJ, Battiste J, Johnson JE, Machold RP, Fishell G (2010) Genetic fate mapping reveals that the caudal ganglionic eminence produces a large and diverse population of superficial cortical interneurons. J Neurosci 30:1582-1594.

Nóbrega-Pereira S, Kessaris N, Du T, Kimura S, Anderson SA, Marín O (2008) Postmitotic Nkx2-1 controls the migration of telencephalic interneurons by direct repression of guidance receptors. Neuron 59:733-745.

Okabe M, Ikawa M, Kominami K, Nakanishi T, Nishimune Y (1997) "Green mice" as a source of ubiquitous green cells. FEBS Lett 407:313-319.

Palmer A, Zimmer M, Erdmann KS, Eulenburg V, Porthin A, Heumann R, Deutsch U, Klein R (2002) EphrinB phosphorylation and reverse signaling: regulation by Src kinases and PTP-BL phosphatase. Mol Cell 9:725-737.

Pasquale EB (2005) Eph receptor signalling casts a wide net on cell behaviour. Nat Rev Mol Cell Biol 6:462-475.

Passante L, Gaspard N, Degraeve M, Frisén J, Kullander K, De Maertelaer V, Vanderhaeghen P (2008) Temporal regulation of ephrin/Eph signalling is required for the spatial patterning of the mammalian striatum. Development 135:3281-3290.

Petryniak MA, Potter GB, Rowitch DH, Rubenstein JL (2007) Dlx1 and Dlx2 control neuronal versus oligodendroglial cell fate acquisition in the developing forebrain. Neuron 55:417-433.

Peuckert C, Wacker E, Rapus J, Levitt P, Bolz J (2008) Adaptive changes in gene expression patterns in the somatosensory cortex after deletion of ephrinA5. Mol Cell Neurosci 39:21-31.

Polleux F, Whitford KL, Dijkhuizen PA, Vitalis T, Ghosh A (2002) Control of cortical interneuron migration by neurotrophins and PI3-kinase signaling. Development 129:3147-3160.

Powell EM, Campbell DB, Stanwood GD, Davis C, Noebels JL, Levitt P (2003) Genetic disruption of cortical interneuron development causes region- and GABA cell type-specific deficits, epilepsy, and behavioral dysfunction. J Neurosci 23:622-631.

Rudolph J, Zimmer G, Steinecke A, Barchmann S, Bolz J (2010) Ephrins guide migrating cortical interneurons in the basal telencephalon. Cell Adh Migr 4:400-408.

Uziel D, Mühlfriedel S, Zarbalis K, Wurst W, Levitt P, Bolz J (2002) Miswiring of limbic thalamocortical projections in the absence of ephrin-A5. J Neurosci 22:9352-9357.

Uziel D, Mühlfriedel S, Bolz J (2008) Ephrin-A5 promotes the formation of terminal thalamocortical arbors. Neuroreport 19:877-881. 
Wahl S, Barth H, Ciossek T, Aktories K, Mueller BK (2000) Ephrin-A5 induces collapse of growth cones by activating Rho and Rho kinase. J Cell Biol 149:263-270.

Wang Y, Li G, Stanco A, Long JE, Crawford D, Potter GB, Pleasure SJ, Behrens T, Rubenstein JL (2011) CXCR4 and CXCR7 have distinct functions in regulating interneuron migration. Neuron 69:61-76.

Wonders CP, Anderson SA (2006) The origin and specification of cortical interneurons. Nat Rev Neurosci 7:687-696.

Xu Q, Mellitzer G, Robinson V, Wilkinson DG (1999) In vivo cell sorting in complementary segmental domains mediated by Eph receptors and ephrins. Nature 399:267-271.

Xu Q, Cobos I, De La Cruz E, Rubenstein JL, Anderson SA (2004) Origins of cortical interneuron subtypes. J Neurosci 24:2612-2622.

Yozu M, Tabata H, Nakajima K (2005) The caudal migratory stream: a novel mi- gratory stream of interneurons derived from the caudal ganglionic eminence in the developing mouse forebrain. J Neurosci 25:7268-7277.

Zimmer G, Kästner B, Weth F, Bolz J (2007) Multiple effects of ephrin-A5 on cortical neurons are mediated by SRC family kinases. J Neurosci 27:5643-5653.

Zimmer G, Garcez P, Rudolph J, Niehage R, Weth F, Lent R, Bolz J (2008) Ephrin-A5 acts as a repulsive cue for migrating cortical interneurons. Eur J Neurosci 28:62-73.

Zimmer G, Schanuel SM, Bürger S, Weth F, Steinecke A, Bolz J, Lent R (2010a) Chondroitin sulfate acts in concert with Semaphorin 3a to guide tangential migration of cortical interneurons in the ventral telencephalon. Cereb Cortex 20:2411-2422.

Zimmer G, Gerstmann K, Kaestner B, Bolz J (2010b) Ephrin-a5 affects the laminar organisation of the neocortex. Int J Dev Neurosci 28:655. 